\title{
علاقة التمكين بتدعيم فاعلية آداء فرق العمل بالمؤسسات الرياضية
}

* أ.د حسن أحمد الثافعى

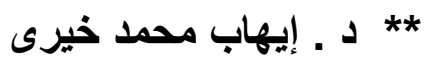

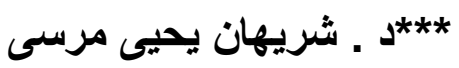

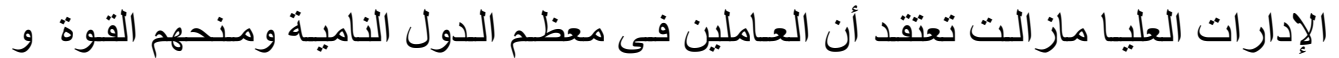

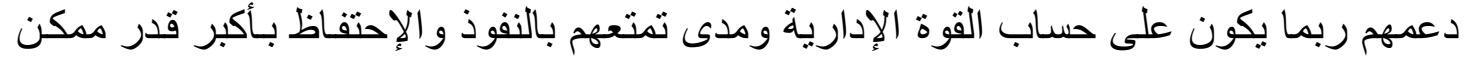

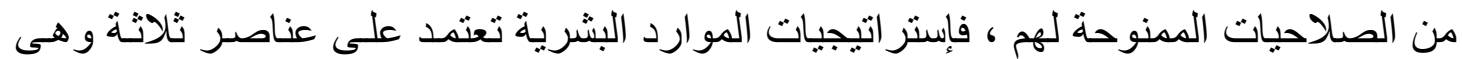

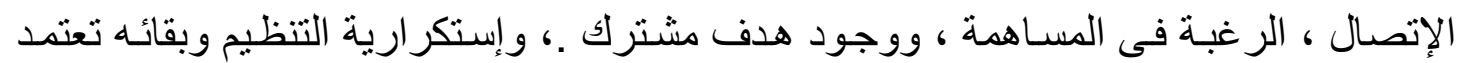

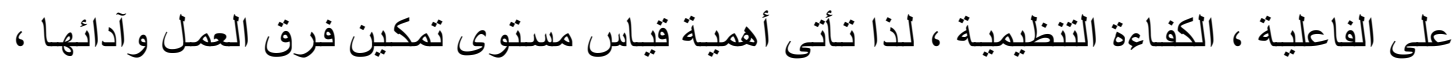

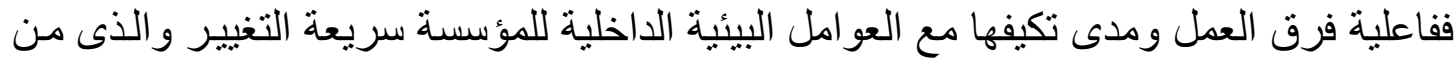

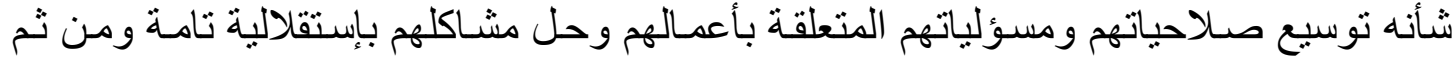

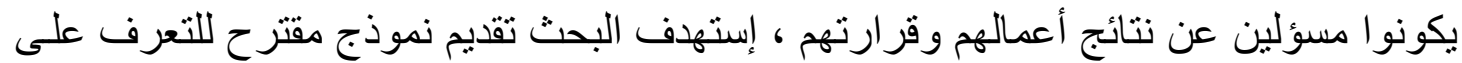

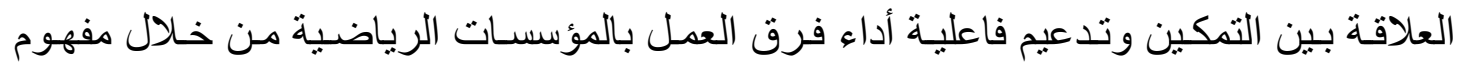

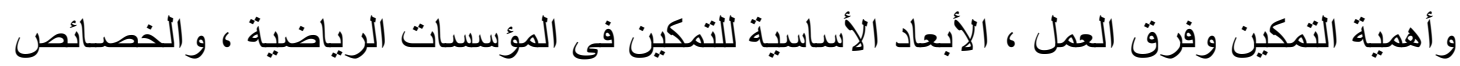

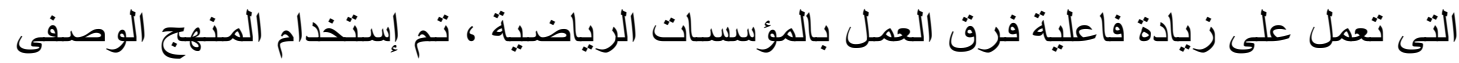

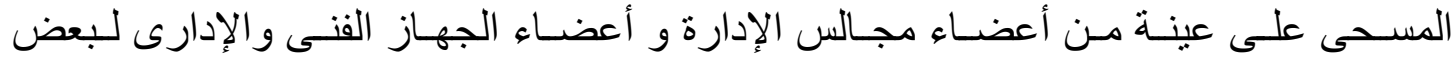

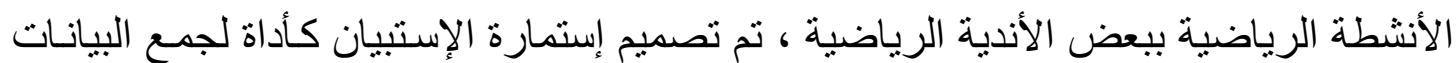

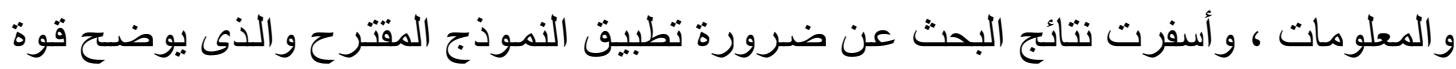

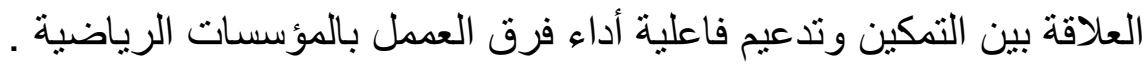

* أستاذ الإدارة الرياضية ورئيس قسم الأدارة الرياضية الأسبق ـ كلية التربية الرياضية بنـات

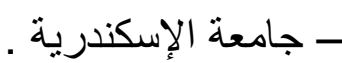
**مدس بقسم الإدارة و الترويح الرياضى ـ كلية التربية الرياضية ـ جامعة طنطا . ***مرس بقسم الإدارة والترويح الرياضى ـ كلية التربية الرياضية ـ جامعة طنطا . 


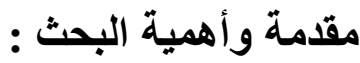

إزداد حجم مؤسسات الأعمال و تأثثير ها فى المجتمعات و إزدادت الإحتياجات الفرديـة الإدية

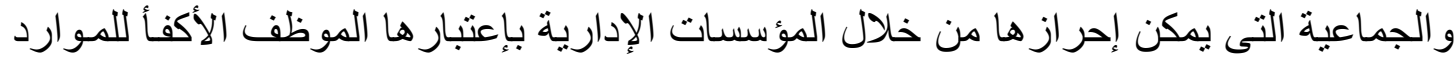

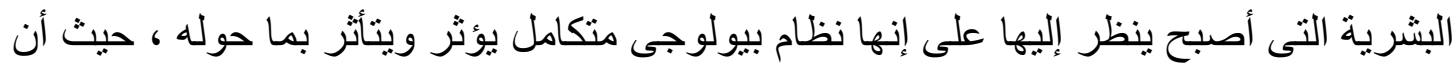

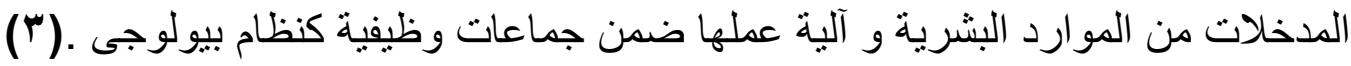

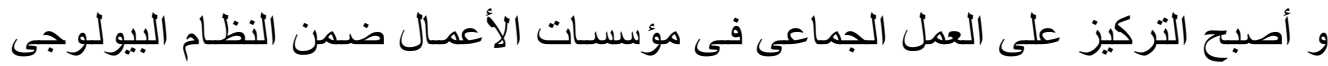

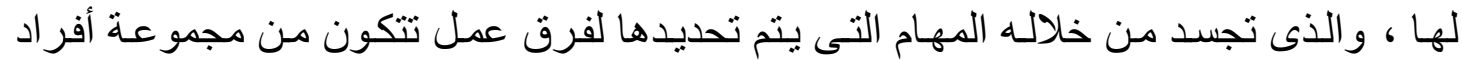
متماسكين يكملون بعضهم البعض في المسئولية .

أضاف ماهر أحمد V . . ب أن زيادة التركيز على العنصر البشرى وممارساته للأنشطة

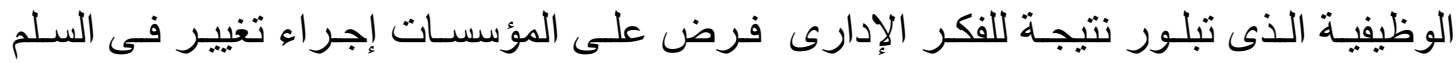

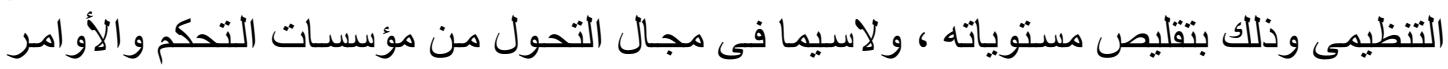

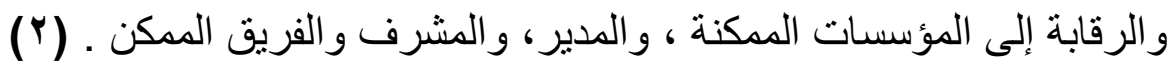

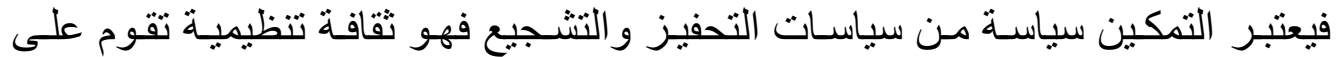

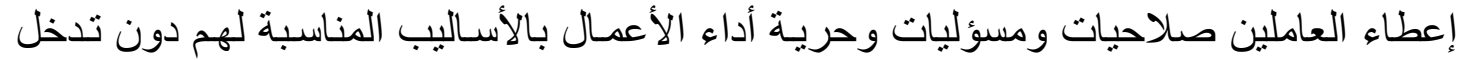

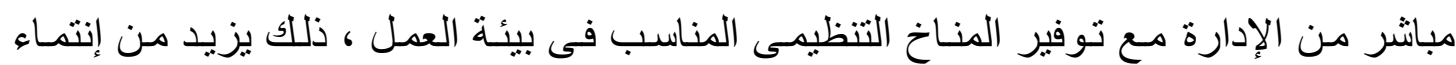

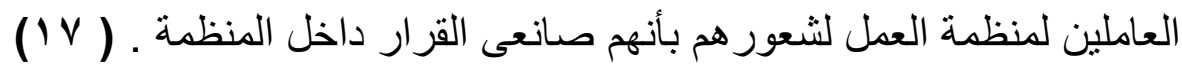
ظهر مفهوم التمكين كمنهج لإدارة الأفر اد من وجهه نظر الكثير من الكتاب و النظر إليه

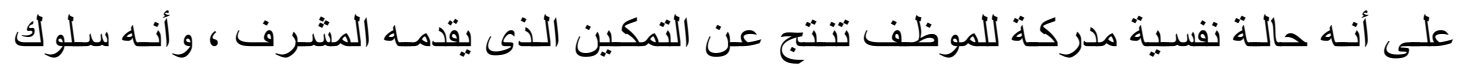
المشرف الذى يمكن مرؤوسيه و بذلك السلوك فإن المشرف يُنظر إليه على أنه مسبب التمكين . لأليه

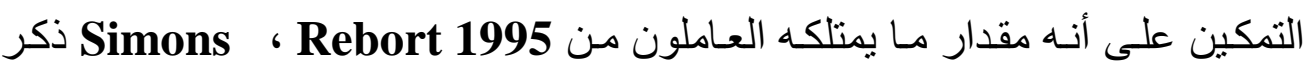

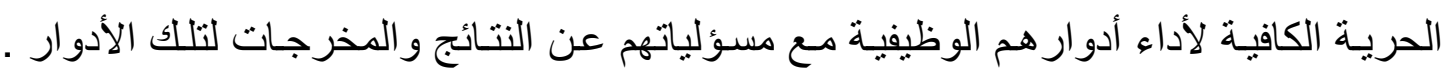
(ro)

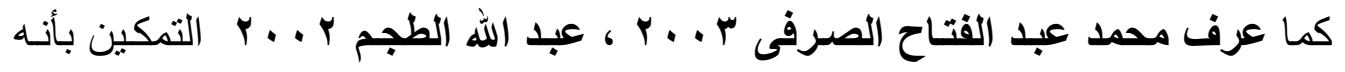

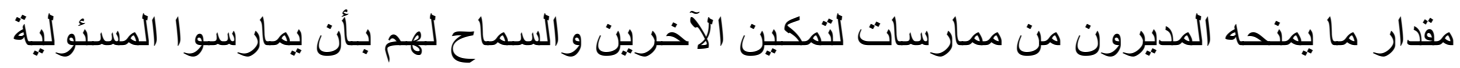

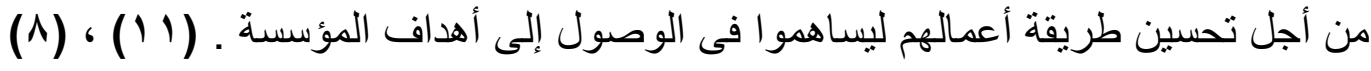

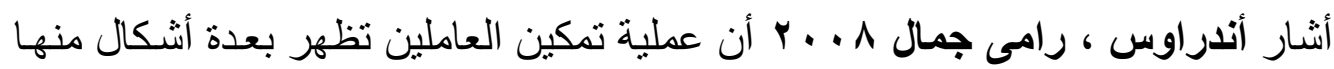

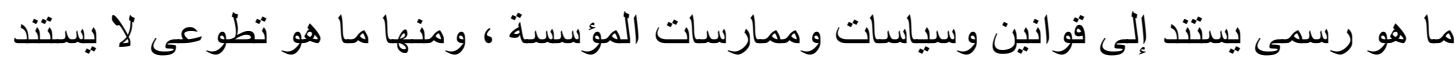

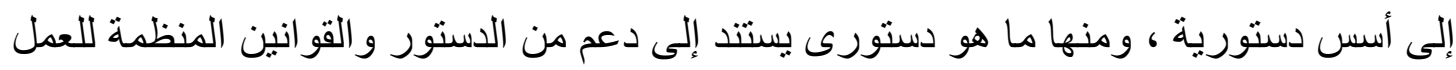

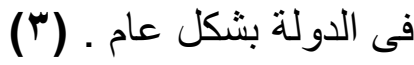


وذكر 1998 Wikinson أن للتمكين عدة تصنيفات لخصها فى :

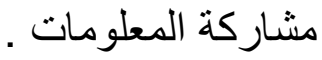

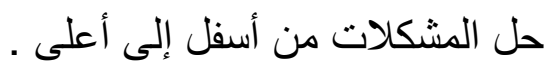
$(r v)$

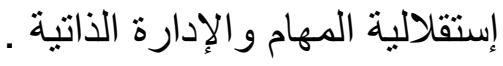

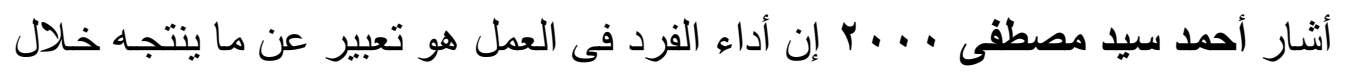

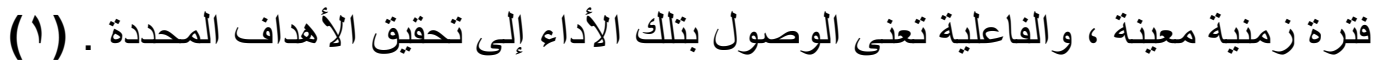
و أضـاف James Becker 2001 أن الأداء الوظيفى هو أهم محاور فاعلية الأداء

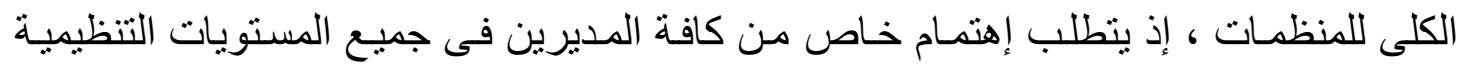

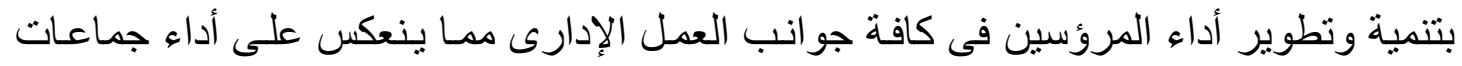

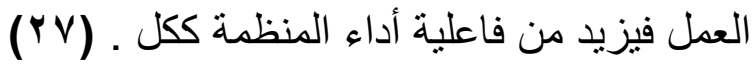

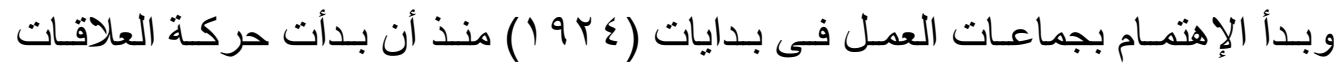

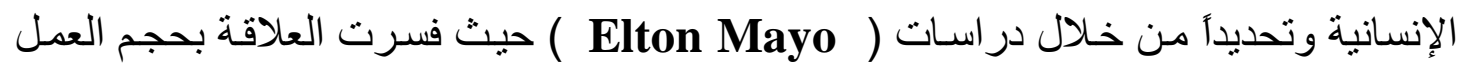

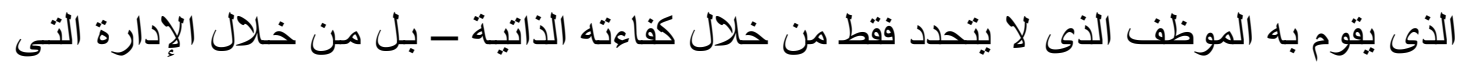

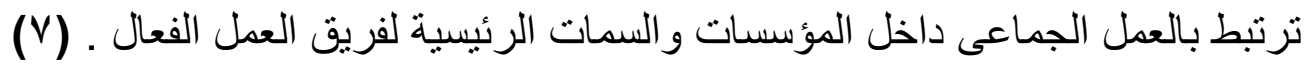
فذكر 2000 Daft فرق أو جماعات العمل على أنها وحدة مكونة من فردين أو أكثر

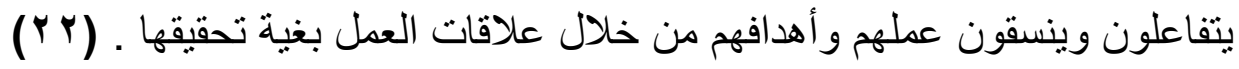

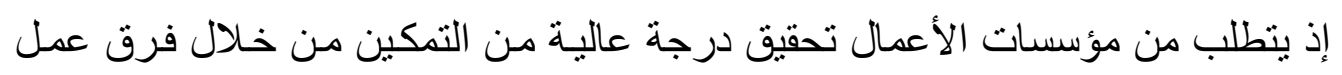

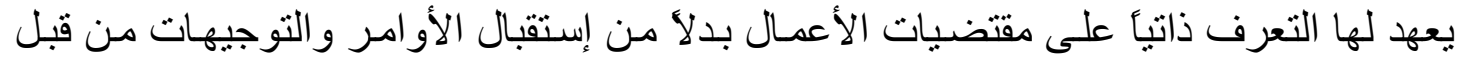

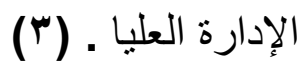

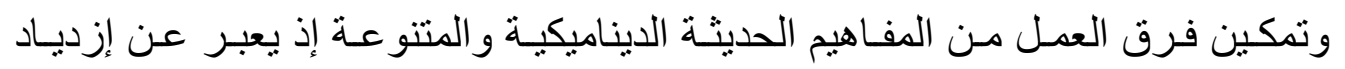

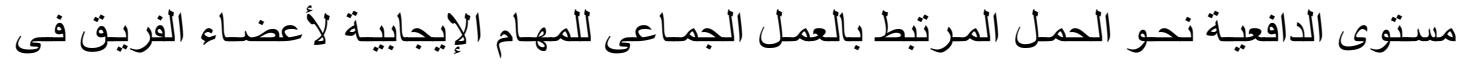

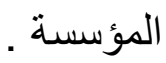
عرف الع 2006 Oberty تمكين فرق العمل على أنه مقدار زيادة تحفيز أعضـاء فرق

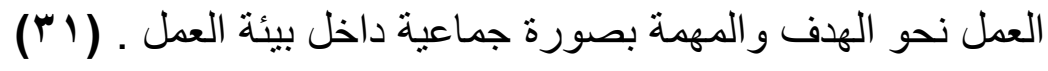

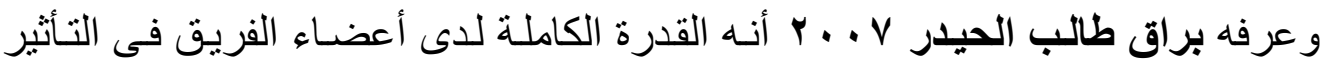

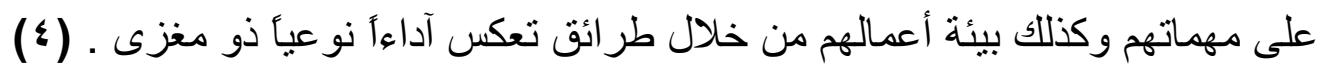

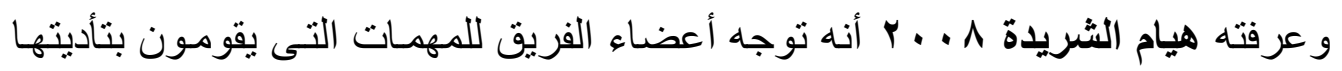

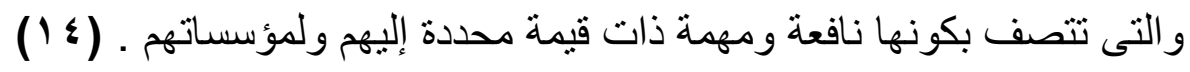
لذا فإن لفرق العمل ذات مكانه فى مجال التمكين الإدارى كإحدى الأليات الأساسية

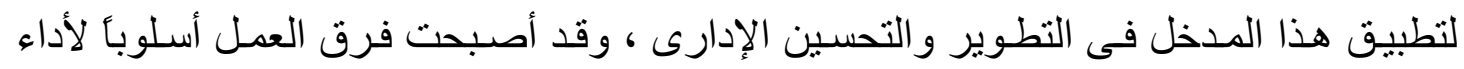


الأعمال ، وعلى من هم يريدون النجاح فى علم الإدارة ويهدفون إلى تطبيق التمكين الإدارى أن

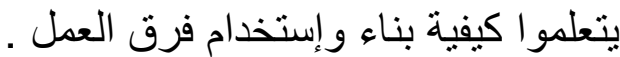

وفرق العمل هنا وسيلة لتحقيق هدف وهو التمكين الإدارى ، وقد يتمثل ذلك في زيادة

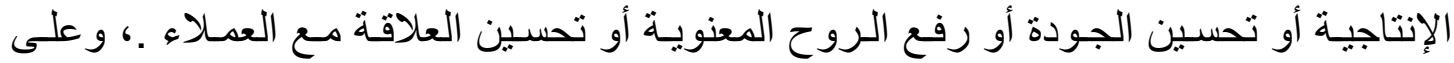

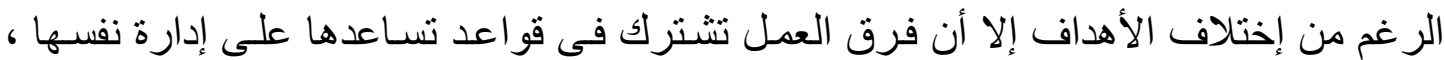
ومن أهم مميزات فرق العتاف الاهل : العمل

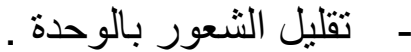

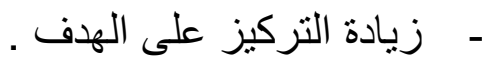

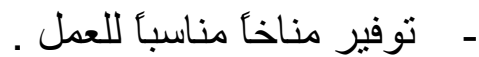

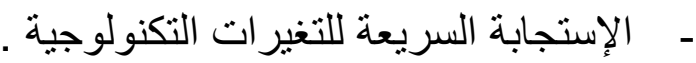

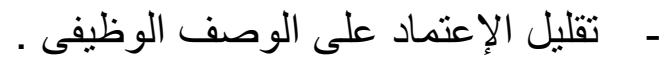
-

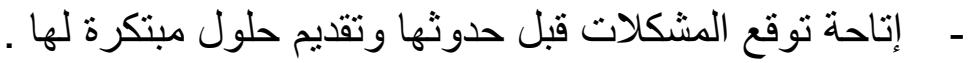

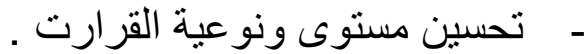

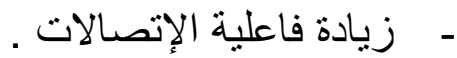

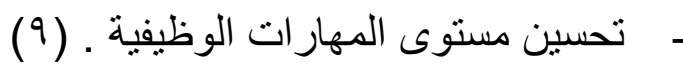

وذكر 2014Amr Abou Elnaga أن فاعلية فرق العمل تتحقق عندما تتطابق

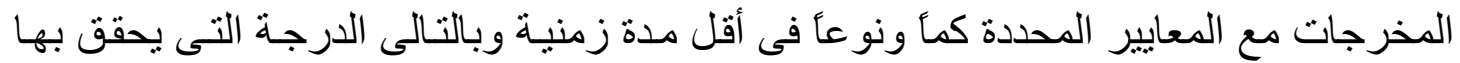

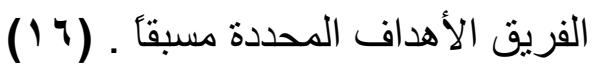

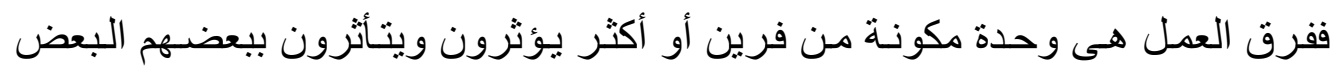

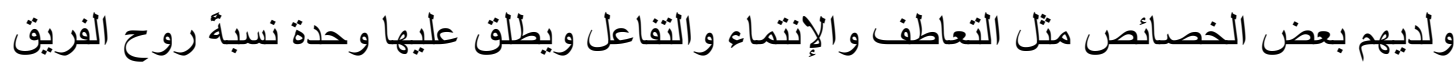

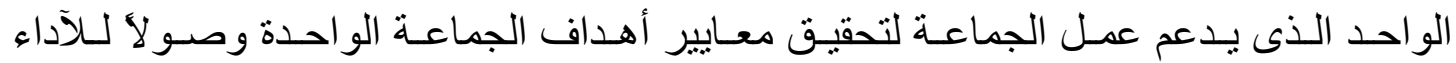

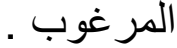

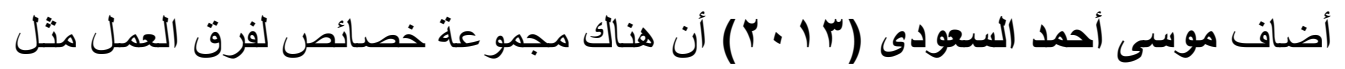

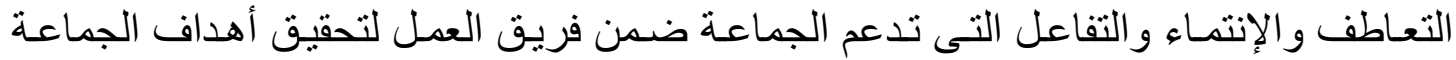

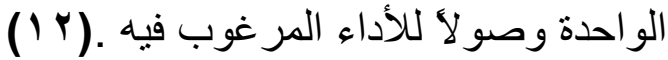

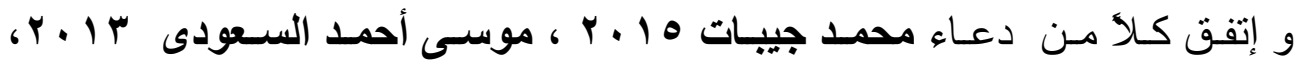
Invacevich 2002

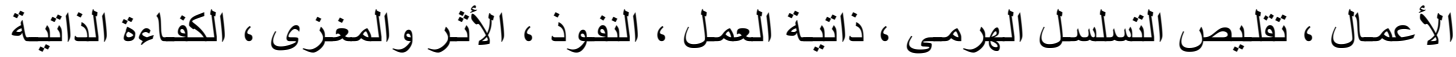

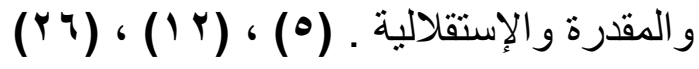

2006 Mendibil ؤنه يمكن تقسيم تمكين فرق العمل لثناث مستويات : 


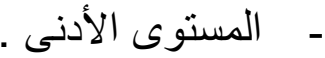

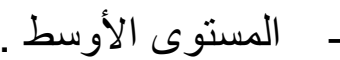

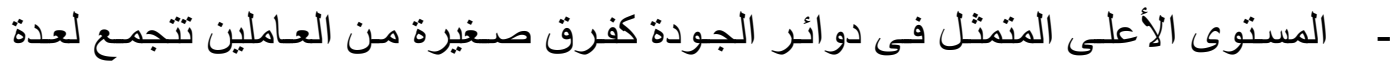

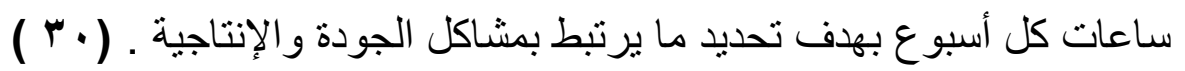

كمـا أوضـح ( Spector ) أن هنـاك بعدان أساسيان لتمكين فرق العمل من الناحيـة

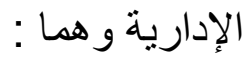

- البعد المهارى ويقصد بـه مـا يكتسبه الفرد من مهار ات العمل الجمـاعى عن طريق

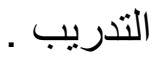

- البعد الإدارى ويقصد به تمتع كل فرد فى المنظمـة بالقدر الكافى من حريـة وصـاحية

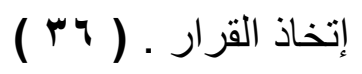

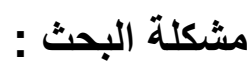

هناك جانبان جوهريان فى التنظيمات هما ( العمل ، السلوك ) فبعض الباحثين فى علم

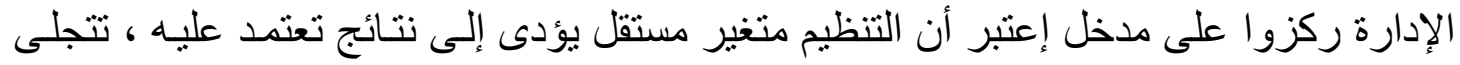

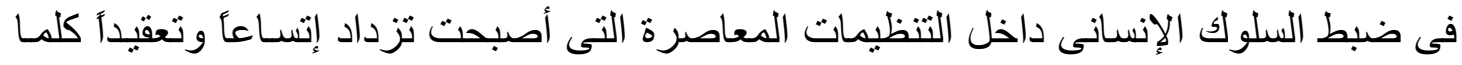

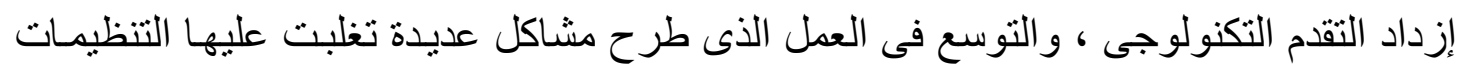

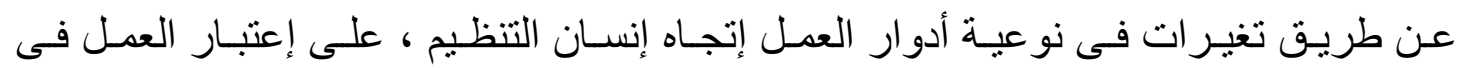

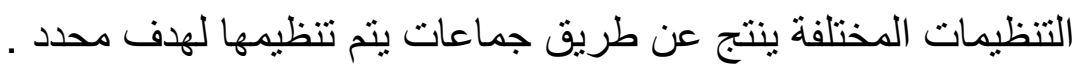

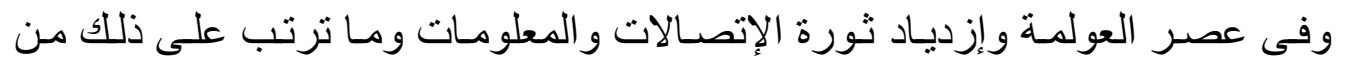

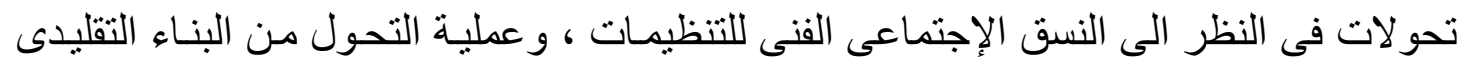

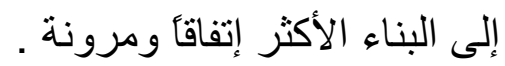

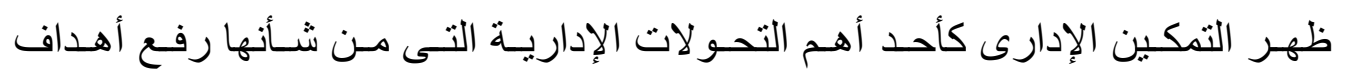

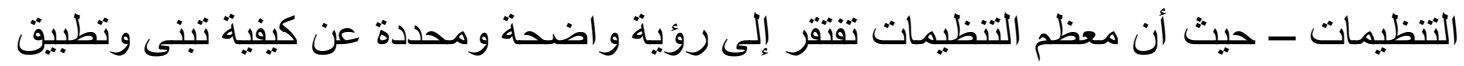

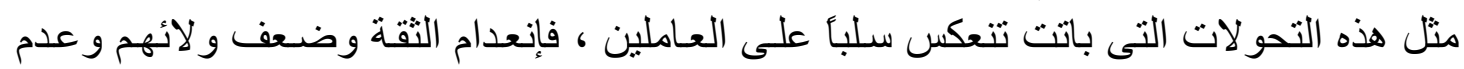
إلتز امهم فى العمل يؤدى إلى ضعف لآلى الآداء الوظيفى .

كما أن الإدارات العليا ماز الت تعتقد أن تمكين العاملين فى معظم الدول النامية ومنحهم

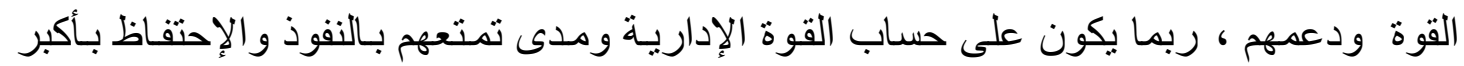

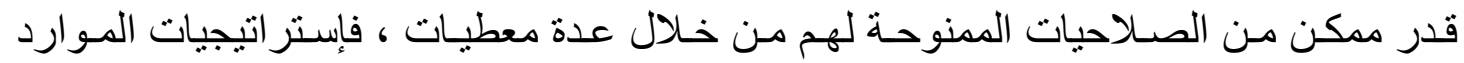

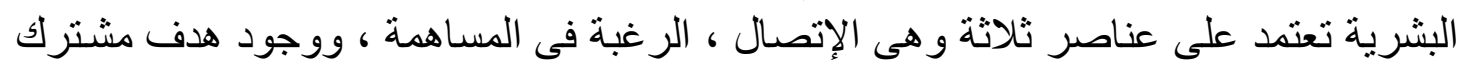

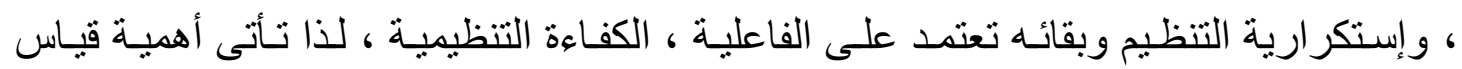

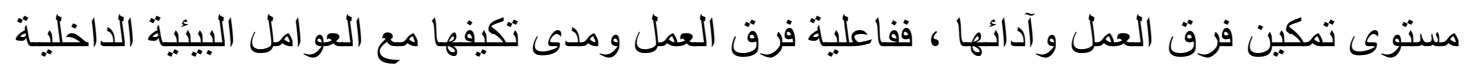

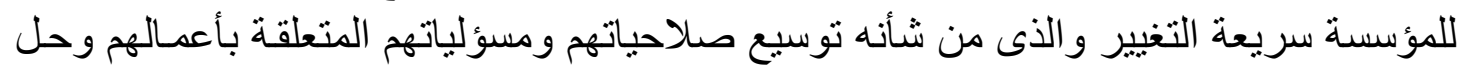

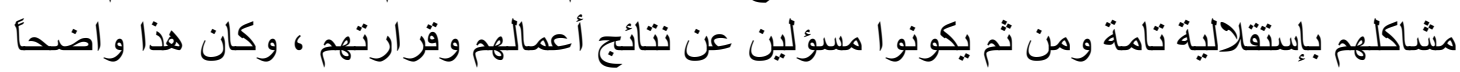

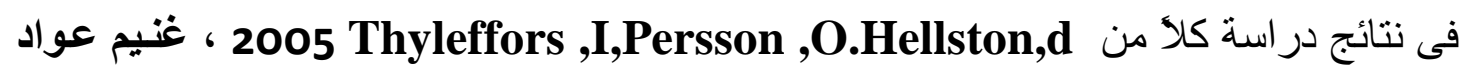




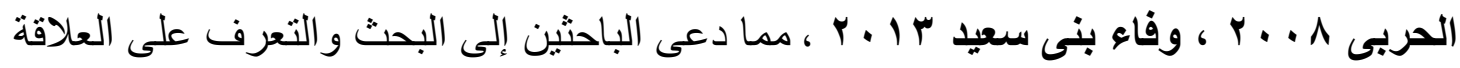

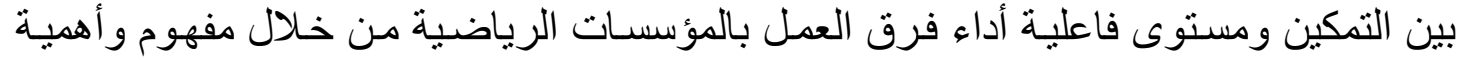

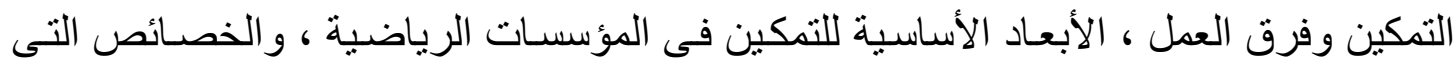
تعمل على زيادة فاعلية فرق العمل بالمؤسسات الرياضية الأيكية .

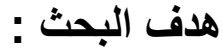

يهرف البحث إلى تقديم نموذج يوضـح العلاقة بين التمكين وتدعيم فاعلية أداء فرق العمل بالمؤسسات الرياضية من خلال :

1 - مفهوم التمكين وفرق العمل بالمؤسسات الرياضية .

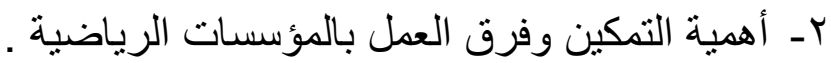

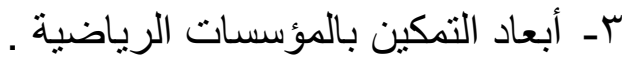
ع - الخصائص التى تعمل على زيادة فاعلية فرق العمل بالمؤسسات الرياضية .

\section{التعريف ببعض المفاهيم والمصطلحات المستخدمة فى البحث :}

التمكين : هو عمليـة لتعزيز الإحساس بالإندماج الوظيفى والإبتعاد عن الإحساس بالعزلئة و الإعتماد على الذات من خلال تحديد الظروف التى لتى تمنح القوة و الحرية فى المشـاركة في إنجاز

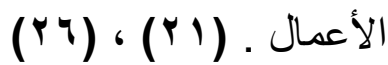
فرق العمل : مجموعة من الأفر اد يتمتعوا بكفايات تكاملية ويتعهدو ا فيما بينهم بالإلتز ام لتحقيق أهداف مشتركة تتو افق مع رسالة المؤسسات المختلفة ـ (تعريف إجرائى)

الفاعلية : هى الوصول بأداء الفرد إلى تحقيق الأهداف المطلوبة منه ـ (1)

$$
\text { إجراعات البحث }
$$

منهج البحث : إستخدم الباحثين المنهج الوصفى وذلك لملاءمته لطبيعة البحث و أهدافه .

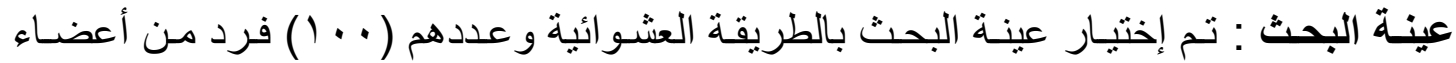

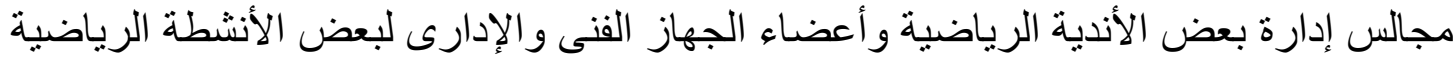

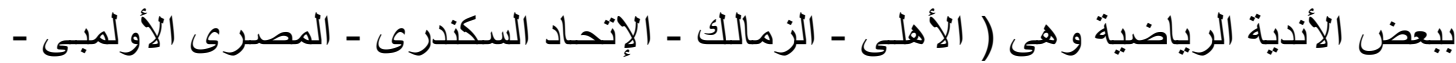

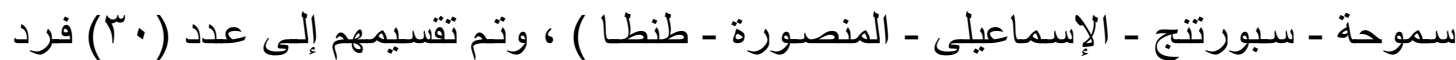

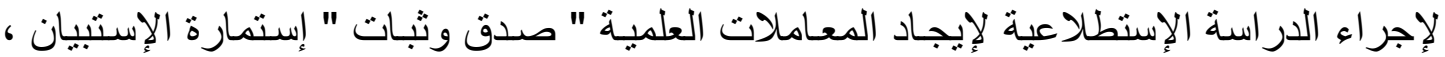

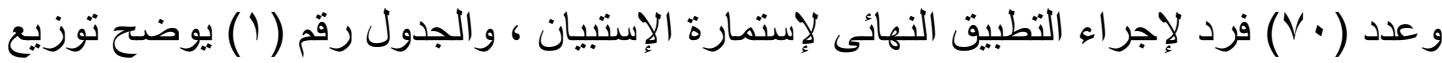




\begin{tabular}{|c|c|c|c|c|}
\hline النهائى العـد & 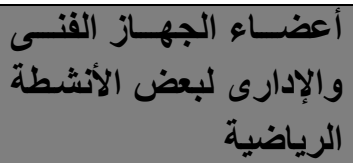 & 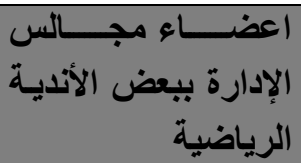 & عينة الدراسة & $p$ \\
\hline$r$. & 19 & 11 & 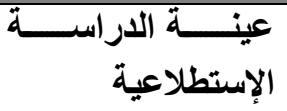 & 1 \\
\hline V. & $\varepsilon$ & $r \cdot$ & 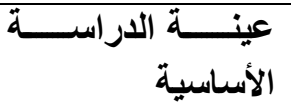 & $r$ \\
\hline $1 \ldots$ & 09 & $\leqslant 1$ & & الم \\
\hline
\end{tabular}

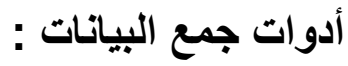

- المستح المرجعى : للقر اءات النظريـة للمر اجـع العلميـة و الدر اسـات المرتبطـة بموضوع البحث: البمات . - - إستمارة الإستبيان : ( من إعداد الباحثين ) ومرت بالخطوات التالية :

تم عرض إستطلاع رأى على السادة الخبر اء من أعضـاء هيئة التدريس المتخصصين

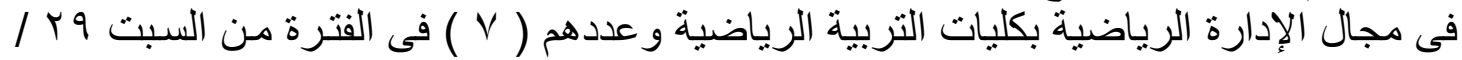

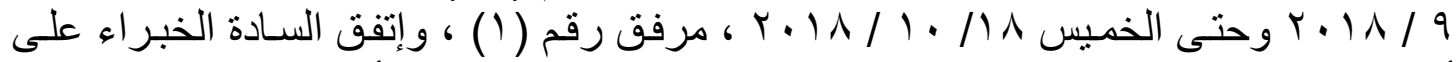

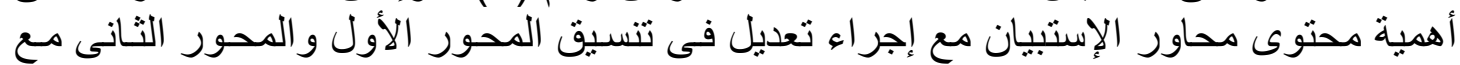

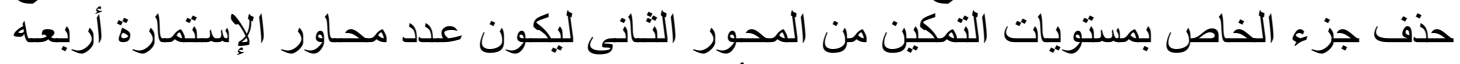

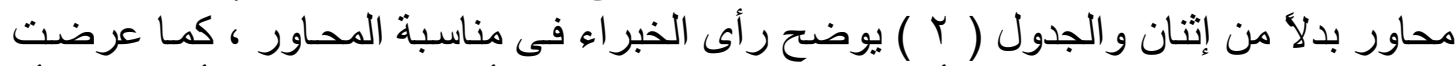

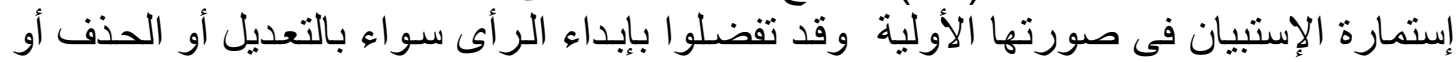

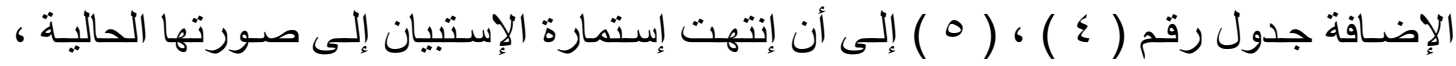

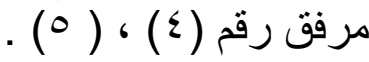

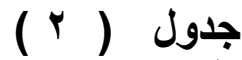

التكرار والنسبة المئوية والأهية النسبية لآراء السادة الخبراء حول محاور استمارة استبيان

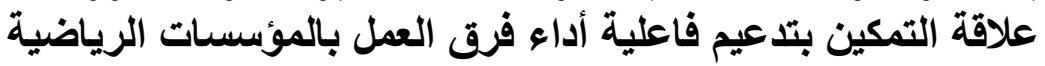

\begin{tabular}{|c|c|c|c|c|c|c|c|}
\hline \multirow{2}{*}{ الأهمية } & \multirow{2}{*}{ النسبى } & \multicolumn{2}{|c|}{ 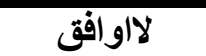 } & \multicolumn{2}{|c|}{ أوافق - } & \multirow{2}{*}{ 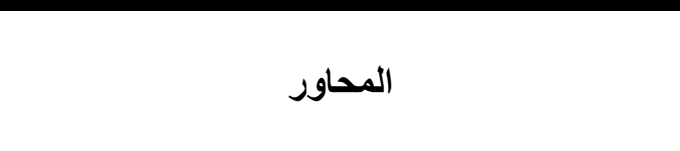 } & \multirow[t]{2}{*}{ b } \\
\hline & & $\%$ & ك5 & $\%$ & ك5 & & \\
\hline $1 \cdots \cdots$ & v & $\because \cdots$ & . & $1 \ldots \ldots$ & V & مفهوم التمكين وفرق العمل بالمؤسسات الرياضية & 1 \\
\hline $1 \ldots \ldots$ & V & $\because \cdots$ & - & $1 \ldots \ldots$ & V & أهمية التمكين وفرق العمل بالمؤسسـات الرياضية & r \\
\hline
\end{tabular}




\begin{tabular}{|c|c|c|c|c|c|c|c|}
\hline & & & & & & أ- أهيّة أهمية التمكين . & \\
\hline A०.VIE & 7 & $1 \leqslant . Y \wedge 7$ & 1 & $\wedge 0 . V 1 \leq$ & 7 & أبعاد التمكين بالمؤسسات الرياضية : & $r$ \\
\hline $1 \ldots \ldots$ & v & $\because \cdots$ & - & $1 \cdots \cdots$ & $\mathrm{v}$ & 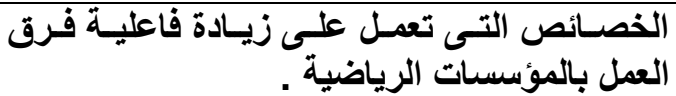 & $\varepsilon$ \\
\hline
\end{tabular}

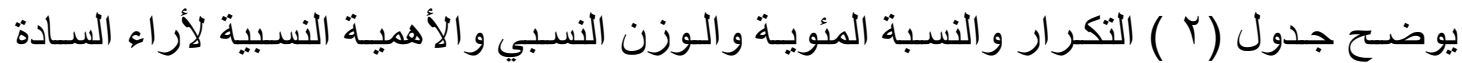

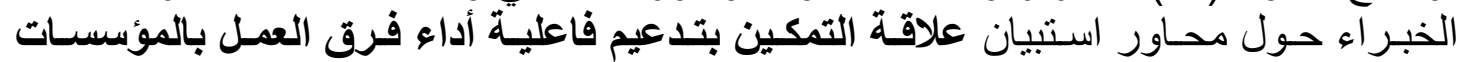

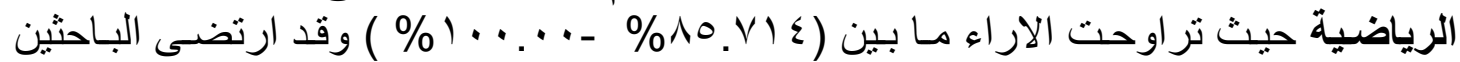

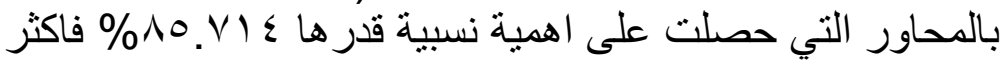

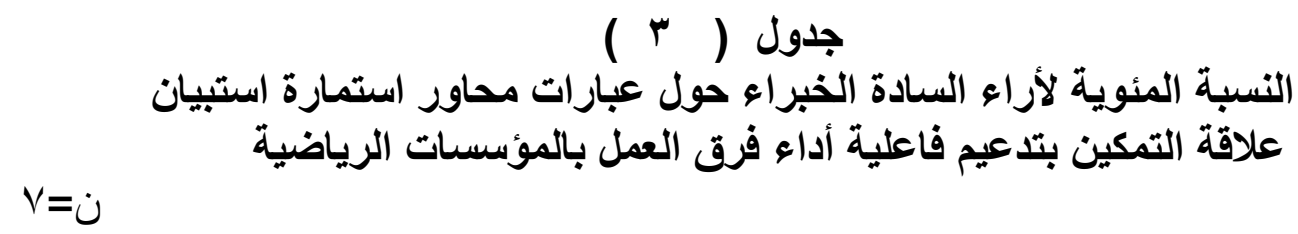

\begin{tabular}{|c|c|c|c|c|c|c|c|}
\hline \multicolumn{2}{|c|}{ المحور الر ابع } & \multicolumn{2}{|c|}{ المحور الثالث } & \multicolumn{2}{|c|}{ المحور الثانح } & \multicolumn{2}{|c|}{ المحور الاول } \\
\hline نسبة المو افقة & r & نسبة المو افقة & r & نسبة المو اققة & 5 & نسبة المو افقة & r \\
\hline 10.VI $\leq$ & ro & $\cdots \ldots$ & rT & \multicolumn{2}{|c|}{ |_أهمية التمكين } & \multicolumn{2}{|c|}{ |-مفهوم التمكين } \\
\hline$\ldots \ldots$ & T & $V I . \leqslant Y q$ & $r \varepsilon$ & 人०.VI $\varepsilon$ & 10 & $1 \ldots \ldots$ & 1 \\
\hline $0 V .1 \leqslant r$ & rV & $10 . V 1 \leq$ & ro & $\ldots \ldots$ & 17 & 10.VI $\varepsilon$ & $r$ \\
\hline 10.VI $\varepsilon$ & rᄉ & 10.VI $\varepsilon$ & $r T$ & $\ldots \ldots$ & IV & $\ldots \ldots$ & r \\
\hline$\ldots \ldots$ & rq & $\ldots \ldots$ & TV & $V 1 . \leqslant Y q$ & 11 & $\ldots \ldots$ & $\xi$ \\
\hline$V I . \leqslant Y q$ & $\varepsilon$. & No.VIE & $r \wedge$ & \multicolumn{2}{|c|}{ ب-أهمية فرق } & No.VI $\leq$ & 0 \\
\hline 10.VI $\leqslant$ & $\xi 1$ & $\varepsilon Y . \wedge \circ V$ & rq & $1 \ldots \ldots$ & 19 & AO.VI & 7 \\
\hline$\ldots \ldots$ & $\varepsilon Y$ & $\ldots \ldots$ & r. & $1 \ldots \ldots$ & $r$. & $1 \ldots \ldots$ & $\mathrm{V}$ \\
\hline$V I . \leqslant Y q$ & हा & $\cdots \cdots$ & M & $V 1 . \leqslant r q$ & YI & \multicolumn{2}{|c|}{ ب-مفهوم فرق العمل } \\
\hline 10.VI $\leqslant$ & $\varepsilon \varepsilon$ & $1 \ldots \ldots$ & r & $1 \ldots \ldots$ & rr & $1 \ldots \ldots$ & $\Lambda$ \\
\hline \multirow[t]{3}{*}{$\ldots \ldots$} & $\leqslant 0$ & $V I . \leqslant Y q$ & سץ & & & rA.OVI & 9 \\
\hline & & 10.VIE & r & & & $1 \ldots \ldots$ & 1 . \\
\hline & & & & & & $\ldots \ldots$ & 11 \\
\hline
\end{tabular}




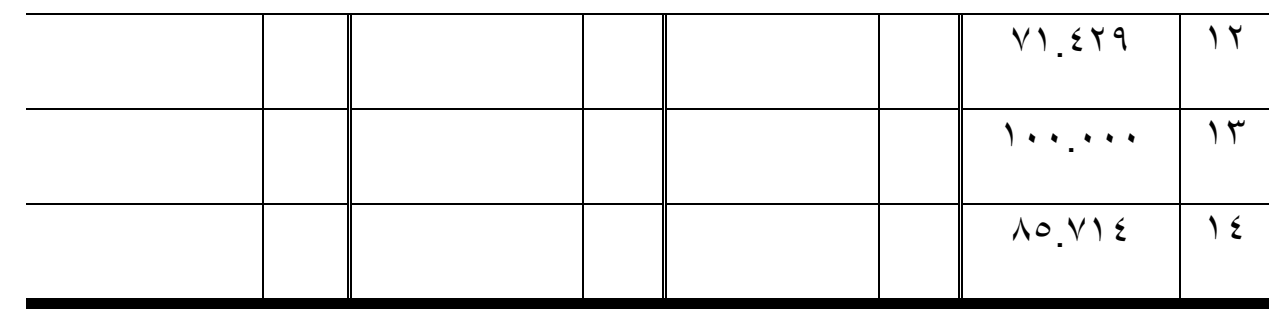

يوضح جدول ( ب) النسبة المئوية لأر اء السادة الخبر اء حول عبار ات استمارة استبيان علاقة

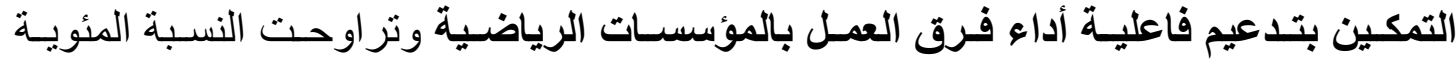

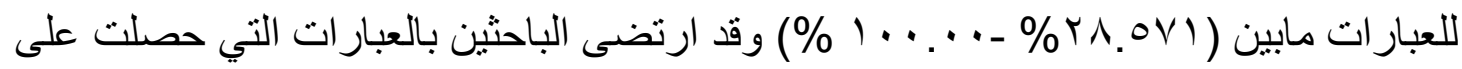

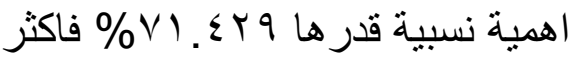

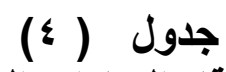

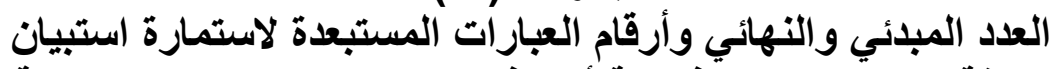

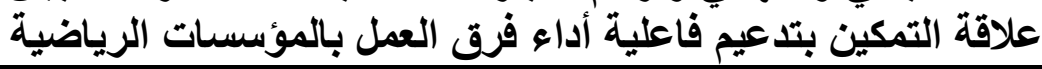

\begin{tabular}{|c|c|c|c|c|c|c|c|}
\hline للعبار العدي & العبار أر الث المعلة & العبار ات المعدلة & أرقام العبار ات المستبعدة & عدد العبار ات & اللعبار اتئي & 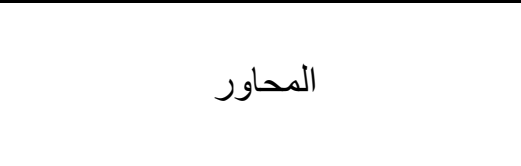 & م \\
\hline T & . & - & 9 & 1 & $1 \leqslant$ & مفهوم التمكين وفرق العمل بالمؤسسات & 1 \\
\hline$\Lambda$ & & 1 & - & & $\Lambda$ & أهمية التمكين وفرق العمل بالمؤسسات & r \\
\hline 11 & . & . & rq & 1 & IT & أبعاد التمكين بالمؤسسات الرياضية . & $r$ \\
\hline 1 . & - & - & re & 1 & 11 & الخصائص التى تعمل على زيادة فاعلية & $\varepsilon$ \\
\hline$\leqslant Y$ & 1 & 1 & $r$ & r & $\leqslant 0$ & الاجمالى & \\
\hline
\end{tabular}

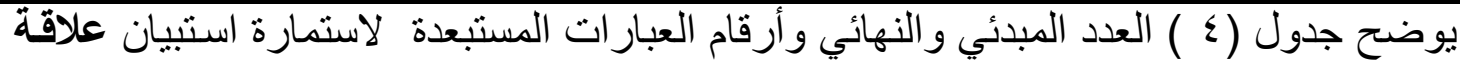

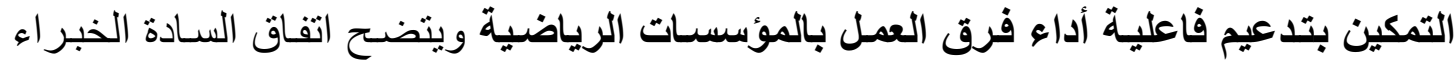

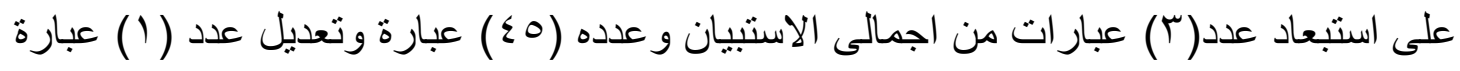

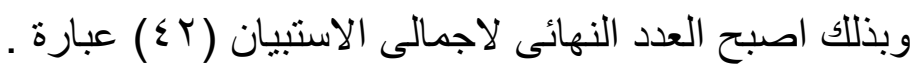

\section{المعاملات الإحصائية لإستمارة الإستبيان :}

- الصداق : إضـافة إلى صـدق المحكمين ، تم إيجـاد صـدق الإتسـاق الـاخلي لإسـتمارة

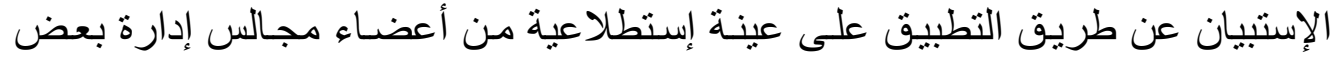

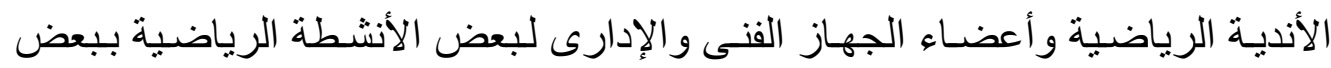

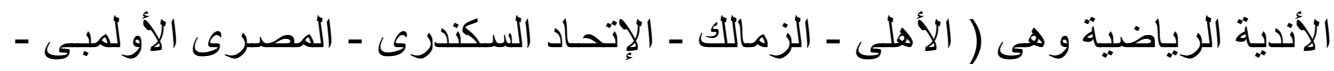

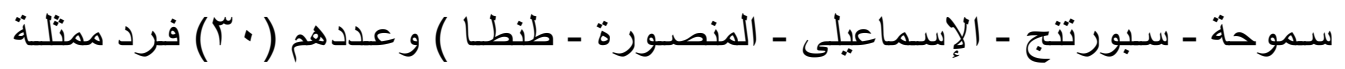




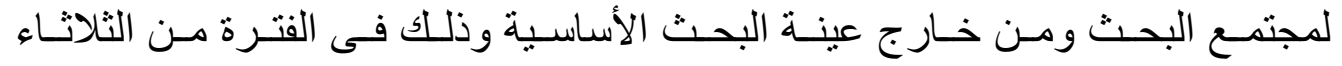

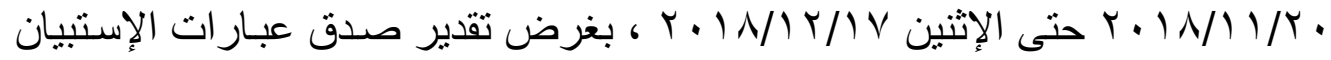

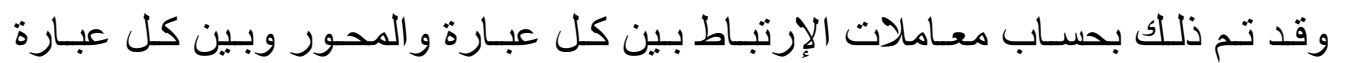

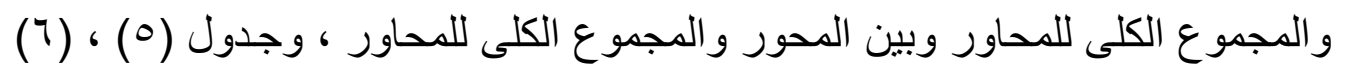

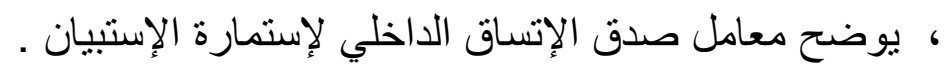

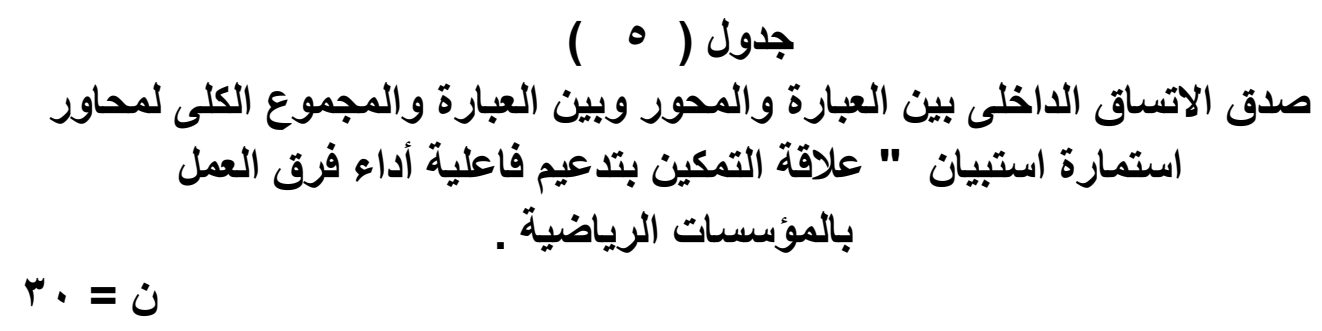

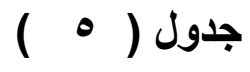

صدق الاتساق الداخلى بين العبارة والمحور وبين العبارة والمجموع الكلى لمحاور

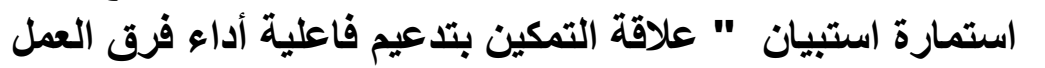

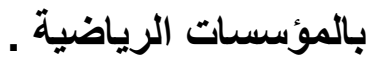

$r \cdot=\dot{0}$

\begin{tabular}{|c|c|c|c|c|c|c|c|c|c|c|c|}
\hline \multicolumn{3}{|c|}{ المحور الر ابع } & \multicolumn{3}{|c|}{ المحور الثالث } & \multicolumn{3}{|c|}{ المحور الثانى } & \multicolumn{3}{|c|}{ المحور الأول } \\
\hline العجمع & العبارة & s & العجارة & العحّارة & 5 & العبارة & العبارة & s & العبارة & ة العبار & r \\
\hline$\cdot \wedge \wedge$ & $\cdot . \wedge \varepsilon$ & r & $\cdot \wedge 4$ & $\cdot .91$ & Yr & \multicolumn{3}{|c|}{ اـأهية التمكين بالمؤسسة } & \multicolumn{3}{|c|}{ بالمؤسسات الرياضية التمكين } \\
\hline .91 & $\cdot .19$ & 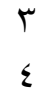 & $\cdot .91$ & $\cdot . \wedge 9$ & rT & .91 & $\cdot A r$ & 1 & $\cdot . \wedge \Lambda$ & $.9 r$ & 1 \\
\hline$\cdot \vee \vee 9$ & $\cdot{ }^{\wedge}$ & $\begin{array}{l}r \\
0\end{array}$ & $\cdot \wedge 4$ & $\cdot .9 r$ & $T \varepsilon$ & $\cdot .17$ & $\cdot \wedge \cdot$ & $\begin{array}{l}1 \\
0\end{array}$ & $\cdot .10$ & $\cdot . \vee 9$ & r \\
\hline$\because \wedge \Lambda$ & $\cdot .10$ & $\begin{array}{l}r \\
T\end{array}$ & $\cdot . \wedge r$ & $\cdot \wedge \vee$ & ro & •.Ar & $\cdot 9$ & $\begin{array}{l}1 \\
7\end{array}$ & $\because \wedge \vee$ & .9 & r \\
\hline$\cdot .17$ & $\cdot .9$ & $\begin{array}{l}r \\
v\end{array}$ & $\cdot \wedge \varepsilon$ & $\cdot .9$ & rq & $\cdot .91$ & $\cdot . \wedge \varepsilon$ & i & $\because \wedge \Lambda$ & $\cdot \wedge \varepsilon$ & $\varepsilon$ \\
\hline$\cdot . \wedge \varepsilon$ & $\cdot . \wedge 1$ & $\begin{array}{l}r \\
\Lambda\end{array}$ & $\cdot . \wedge r$ & $\cdot . \wedge 9$ & TV & اضعبة & أهوئة فر الر & & $\cdot . \lambda r$ & .9 & 0 \\
\hline.$\wedge V$ & $\cdot . \wedge \varepsilon$ & $\begin{array}{l}r \\
q\end{array}$ & $\therefore \wedge \mathrm{V}$ & $\cdot .9$. & $r \wedge$ & $\cdot . \wedge \varepsilon$ & $\cdot . \wedge \wedge$ & $\begin{array}{l}1 \\
1\end{array}$ & $\cdot . \wedge \mathrm{V}$ & • & 7 \\
\hline •.АT & $\cdot . \wedge \wedge$ & $\varepsilon$ & .91 & $\cdot .10$ & rq & $\cdot . \wedge V$ &.$\wedge r$ & $\begin{array}{l}1 \\
9\end{array}$ & $\cdot . \wedge \Gamma$ & .91 & V \\
\hline$\cdot . \wedge T$ & .9 . & $\varepsilon$ & $\cdot \wedge \varepsilon$ & $\cdot . \wedge \wedge$ & $r$. & $\cdot .10$ & $\cdot 9 \cdot$ & r & العمل & فهوم ف & \\
\hline
\end{tabular}




\begin{tabular}{|c|c|c|c|c|c|c|c|c|c|c|c|}
\hline & & 1 & & & & & & . & ياضبة & سسات & \\
\hline.$\wedge \varepsilon$ & .199 & $\begin{array}{l}\varepsilon \\
\gamma\end{array}$ & $\cdot .19$ & ז & 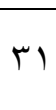 & $\therefore \wedge r$ & $\cdot . \wedge \mathrm{V}$ & $\begin{array}{l}r \\
1\end{array}$ & .9. &.$\wedge \varepsilon$ & $\wedge$ \\
\hline & & & .91 & $\cdot .17$ & $r T$ & & & &. .91 & $\cdot . \wedge \Lambda$ & 9 \\
\hline & & & & & & & & & .91 & $\cdot \wedge V$ & 1. \\
\hline & & & & & & & & & $\cdot . \wedge 7$ & .9. & 11 \\
\hline & & & & & & & & & $\cdot \wedge V$ & $\cdot \lambda r$ & $T r$ \\
\hline & & & & & & & & & $\cdot .^{\wedge} \varepsilon$ & $\cdot \wedge$. & 14 \\
\hline
\end{tabular}

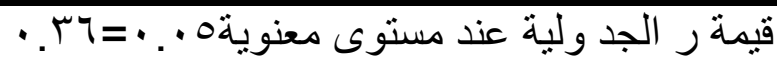

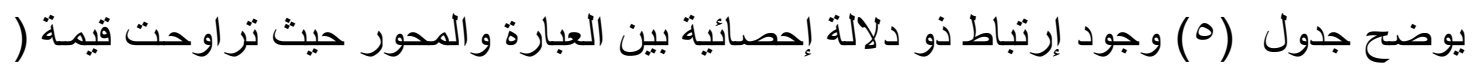

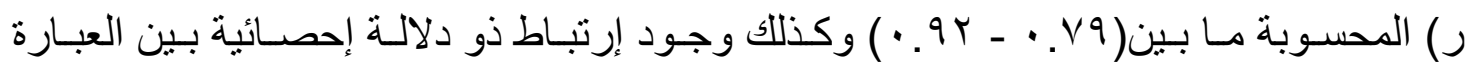

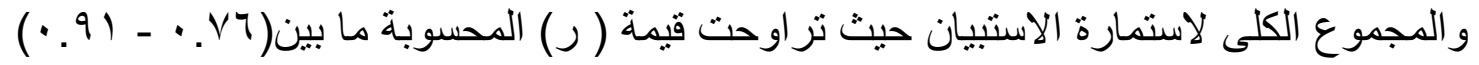

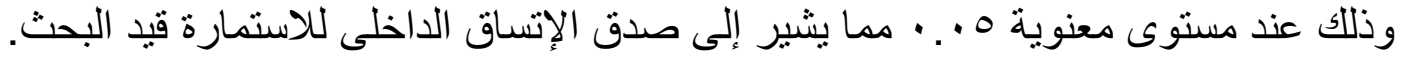

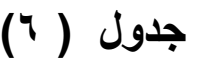

صدق الاتساق الداخلى بين المحور والمجموع الكلى للمحاور لاستمارة استبيان

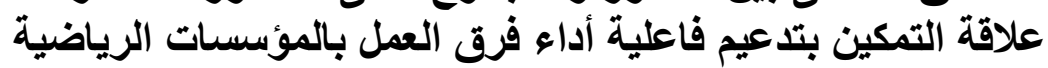

\begin{tabular}{|c|c|c|}
\hline معامل الارتباط & 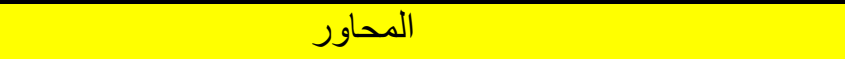 & b \\
\hline.$\wedge 0$ & مفهوم التمكين وفرق العمل بالمؤسسات الرياضية & 1 \\
\hline .91 & أهمية التمكين وفرق العمل بالمؤسسات الرياضية & r \\
\hline$\because \wedge 7$ & أبعاد التمكين بالمؤسسات الرياضية . & r \\
\hline$\cdot . \wedge \wedge$ & الخصائص التى تعمل على زيادة فاعلية فرق العمل بالمؤسسات & $\varepsilon$ \\
\hline
\end{tabular}

$$
\text { قيمة ر الجد ولية عند مستوى معنوية0 . . = ب؟. • }
$$

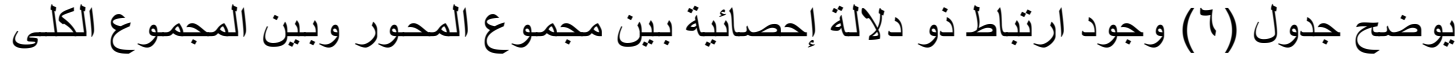

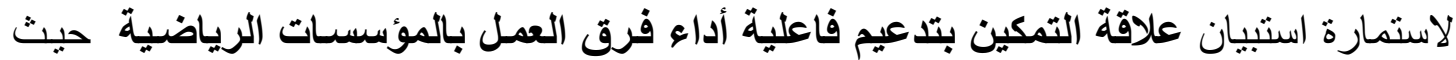

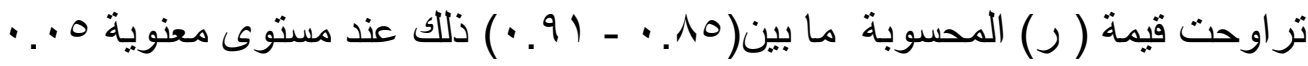

- الثبات : تم حساب معامل الثبات لإستمارة الإستبيان عن طريق إعادة التطبيق ( Test ( Retest 
الرياضية و أعضـاء الجهاز الفنى و الإدارى لبعض الأنشطة الرياضية ببعض الأنديـة

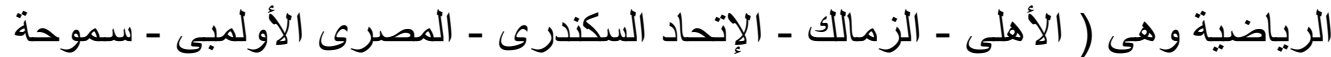

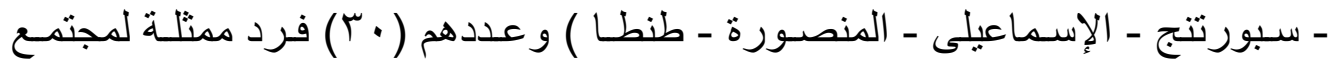

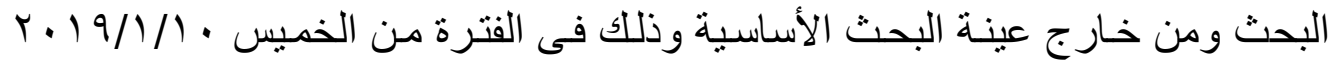

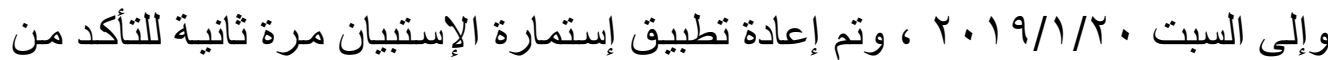

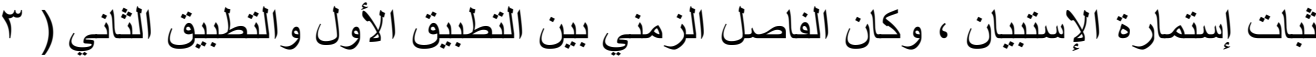

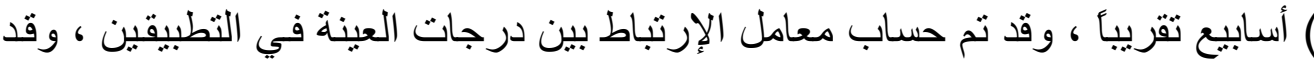

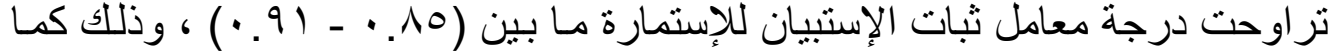

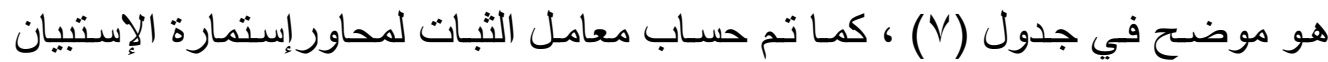

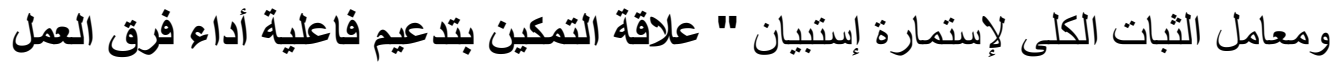

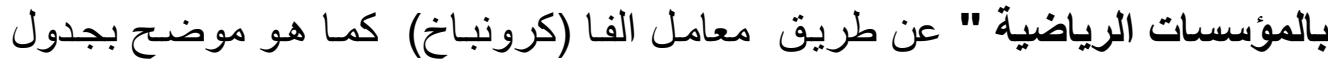

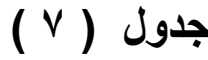

معامل الارتباط بين التطبيق واعادة التطبيق لبيان معامل الثبات لاستمارة استبيان

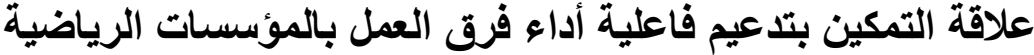

$r \cdot=\dot{~}$

\begin{tabular}{|c|c|c|c|c|c|c|c|}
\hline \multicolumn{2}{|c|}{ المحور الرابع } & \multicolumn{2}{|c|}{ المحور الثالث } & \multicolumn{2}{|c|}{ المحور الثانى } & \multicolumn{2}{|c|}{ المحور الأول } \\
\hline معامل & 5 & الارتباط & s & الارتباط & r & الارتباط & r \\
\hline$\because 9$. & 1 & $\cdot . \wedge r$ & 1 & \multicolumn{2}{|c|}{ اـأهمية التمكين } & \multicolumn{2}{|c|}{ ا-مفهوم التمكين } \\
\hline$\cdot . \wedge r$ & $r$ & .91 & $r$ &.$\wedge 9$ & 1 & $\cdot \wedge \Sigma$ & 1 \\
\hline. .19 & $r$ &.$\wedge$. & $r$ &.$\wedge \wedge$ & $r$ & .91 & $r$ \\
\hline .94 & $\varepsilon$ & .91 & $\varepsilon$ & .94 & $r$ & $\cdot . \wedge 9$ & $\mu$ \\
\hline$\cdot . \wedge \varepsilon$ & 0 &. .19 & 0 & .9 . & $\varepsilon$ & $.9 T$ & $\varepsilon$ \\
\hline.$\wedge V$ & 7 & $\cdot .91$ & 7 & \multicolumn{2}{|c|}{ ب-أهمية فرق } &. .19 & 0 \\
\hline .91 & V & $\cdot . \wedge V$ & V &.$\wedge \varepsilon$ & 0 & 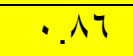 & 7 \\
\hline.$\wedge 0$ & $\wedge$ & $\cdot . \wedge r$ & $\wedge$ & .91 & 7 & .91 & V \\
\hline.$\wedge 9$ & 9 & $\cdot . \wedge \wedge$ & 9 & $\cdot \wedge \wedge$ & V & \multicolumn{2}{|c|}{ ب-مفهوم فرق العمل } \\
\hline$\cdot \wedge \mathrm{V}$ & 1 & $\cdot \wedge 9$ & 1. & $\because \wedge \varepsilon$ & $\wedge$ & $\cdot . \wedge T$ & $\wedge$ \\
\hline
\end{tabular}




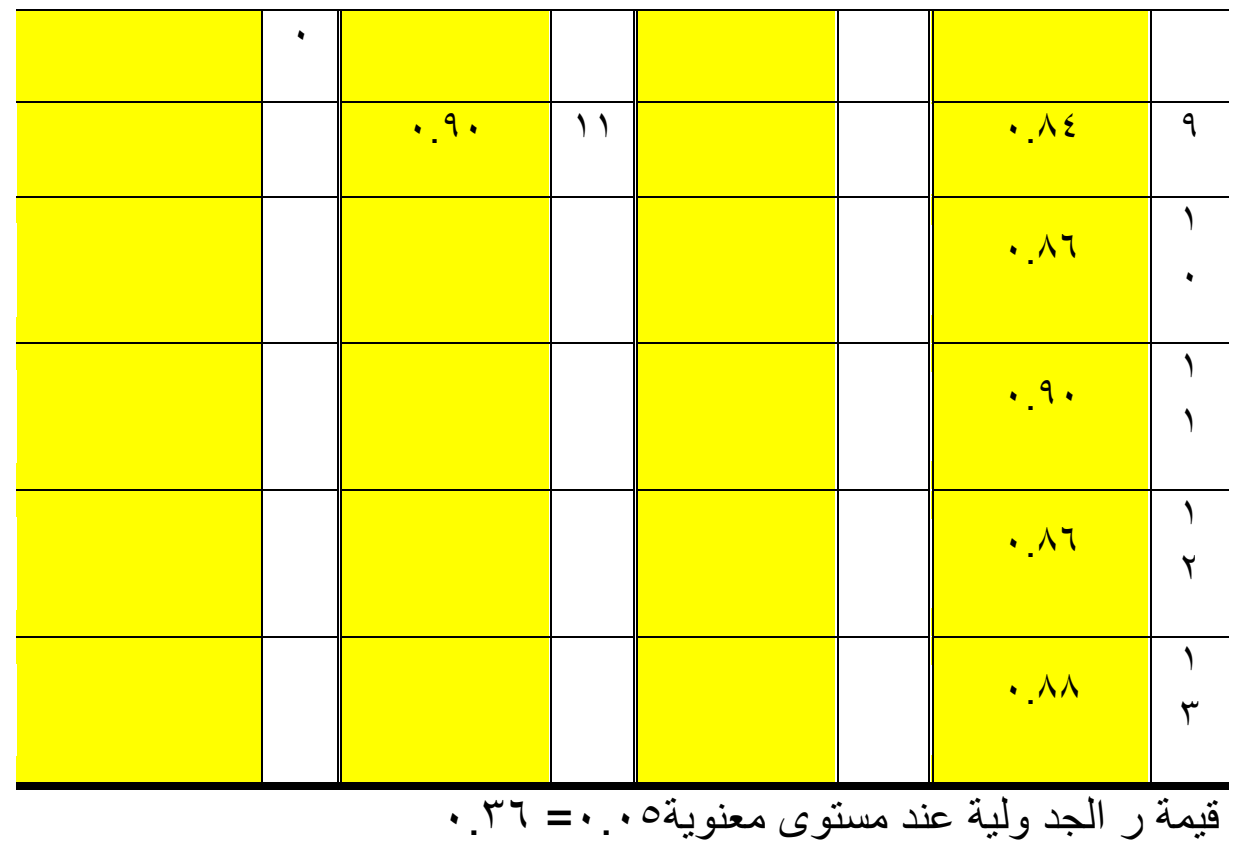

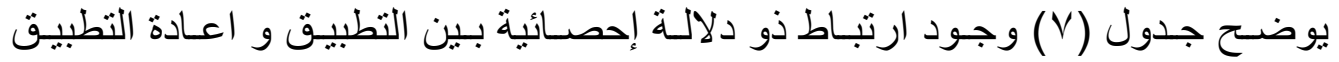

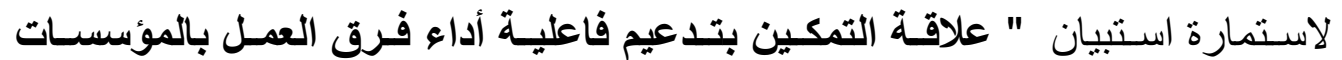

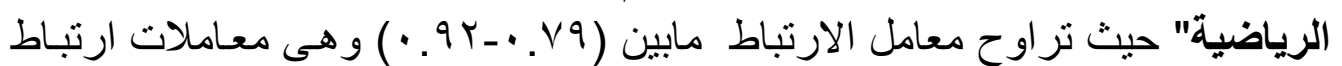
ذو دلالة عالية مما يشير الى ثبات استمارة الاستبيان

\section{جدول (^)}

معامل الفا (كرونباخ) لبيان معامل الثبات لمحاور البحث الاربعة لاستمارة استبيان

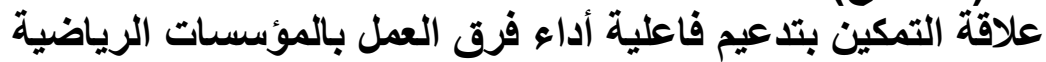
$r \cdot=\dot{0}$

$$
\text { معامل الفا }
$$

$\cdot . \wedge r r$

\begin{tabular}{|c|c|c|}
\hline $\begin{array}{c}\text { Cronbach's Alpha if Item } \\
\text { Deleted }\end{array}$ & المحاور & b \\
\hline$\because \wedge r V$ & مفهوم التمكين وفرق العمل بالمؤسسات الرياضية & 1 \\
\hline$\cdot .119$ & أهمية التمكين وفرق العمل بالمؤسسات الرياضية & r \\
\hline 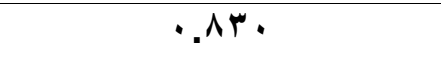 & أبعاد التمكين بالمؤسسات الرياضية . & $r$ \\
\hline$\cdot \wedge r \leq$ & الخصائص التى تعمل على زيادة فاعلية فرق العمل & $\varepsilon$ \\
\hline
\end{tabular}

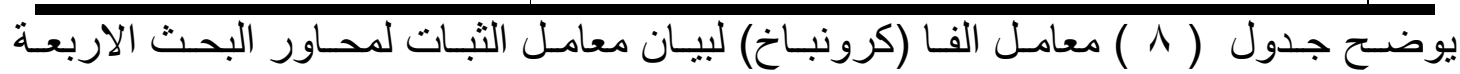

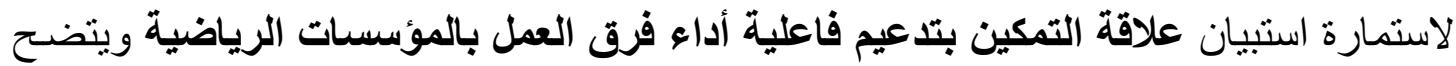
دلالة معامل الفا لمحاور البحث الاربعة. 
بعد التأكد من تو افر كافة الثروط و المعاملات العلميـة لإستمارة إستبيان بحث علاقة

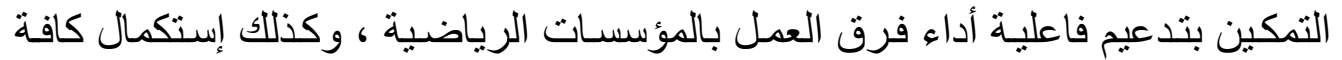

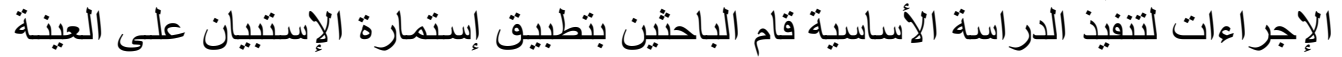

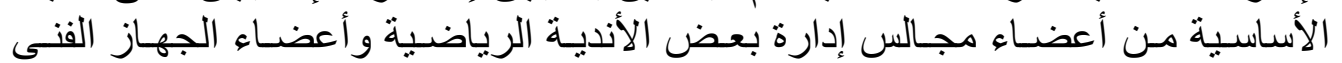

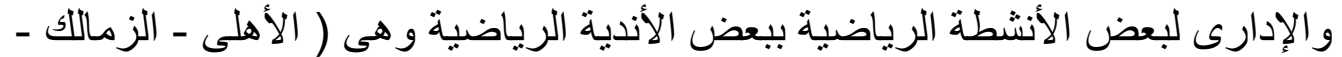

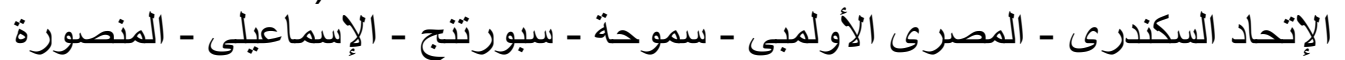

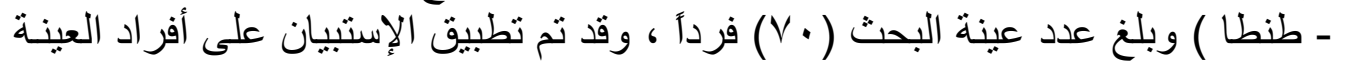

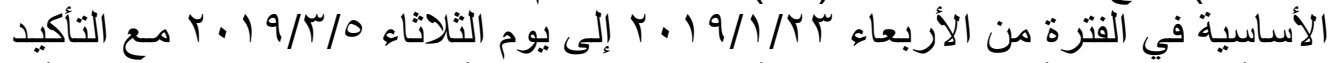

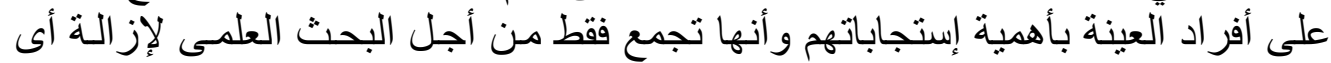

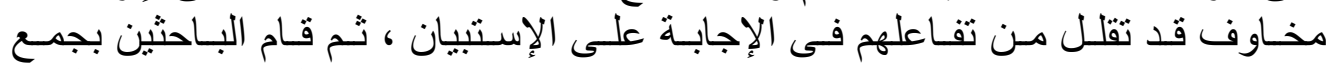

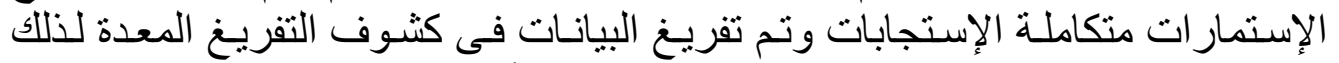

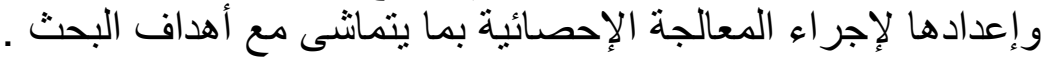

\section{المعالجات الإحصائية للبحث}

إسـتخدم البـاحثين برنـامج الحـزم الإحصـائية SPSS لمعالجـة البيانـات إحصــائياً ،

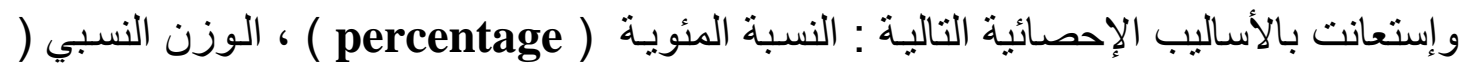
(The relative weight كاr ( chi _ square ) ، و إرتضى الباحثين مستوى معنوية (0. . • ) لقبول النتائج .

عرض ومناقشة نتائج إستمارة إستبيان علاقة التمكين بتدعيم فاعلية أداء فرق العمل بالمؤسسات الرياضية علان

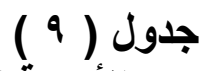

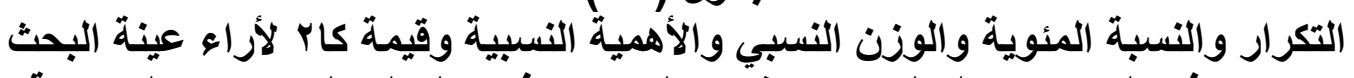

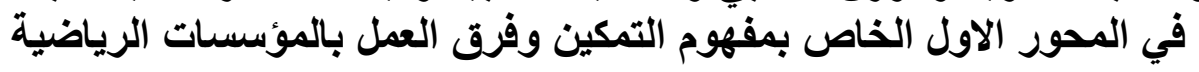

$V \cdot=\dot{U}$

\begin{tabular}{|c|c|c|c|c|c|c|c|c|c|c|}
\hline \multirow[b]{2}{*}{ كاץ } & \multirow{2}{*}{ الأهمية } & \multirow{2}{*}{ النسبي } & \multicolumn{2}{|l|}{$y$} & \multicolumn{2}{|c|}{ إلى حـ ما } & \multicolumn{2}{|l|}{ نعم } & \multirow[b]{2}{*}{ العبارة } & \multirow[b]{2}{*}{ p } \\
\hline & & & $\%$ & ك5 & $\%$ & 5 & $\%$ & 5 & & \\
\hline & & & & & ت الرياضية & & م التمكير & مفهو & أ- & \\
\hline $0 . .$. & $v 1 . \leqslant r q$ & 10. & $r 1 . \leqslant r q$ & 10 & $\varepsilon Y . \wedge \odot V$ & $r$. & ro.VI & ro & 1 & 1 \\
\hline$r q . \& Y q$ & AT.rTr & IVo & $v .1 \leqslant r$ & 0 & ro.VIs & ro & $0 V .1 \leqslant \mu$ & $\varepsilon$. & $r$ & $r$ \\
\hline Ir.oVY & Vr.AI. & 100 & Iะ.YA & 1. & $0 . .$. & ro & ro.VIs & ro & $r$ & $r$ \\
\hline$r r .1 \leqslant r$ & $0 Y . r \wedge 1$ & 11. & $0 . . .$. & ro & $\varepsilon Y . \wedge \odot V$ & $r$. & $V .1 \leq r$ & 0 & $\varepsilon$ & $\varepsilon$ \\
\hline
\end{tabular}




\begin{tabular}{|c|c|c|c|c|c|c|c|c|c|c|}
\hline$r \cdot .7 r q$ & $\Lambda r . \wedge I$. & 187 & Y.A०V & $r$ & $\varepsilon Y . \wedge \odot V$ & $r$. & $0 \leq . Y \wedge \neg$ & $r \wedge$ & 0 & 0 \\
\hline$r Y .1 \leqslant r$ & $\Lambda \cdot .90 r$ & IV. & $V .1 \leqslant r$ & 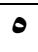 & $\varepsilon Y . \wedge \diamond V$ & $r$. & $0 \ldots \ldots$ & ro & 9 & 7 \\
\hline rq. IVr & $\wedge r . \wedge 1$. & $1 \sqrt{1 V 7}$ & $\varepsilon . Y \wedge \neg$ & $r$ & $\varepsilon \cdot \ldots$ & $r \wedge$ & $00 . V 1 \varepsilon$ & $r q$ & $\mathrm{~V}$ & $\mathrm{~V}$ \\
\hline \multicolumn{11}{|c|}{ ب- مفهوم فرق العمل بالمؤسسات الرياضية } \\
\hline$\varepsilon r . \Delta V Y$ & $\vee \wedge . \diamond \vee I$ & 190 & $\because \cdots$ & . & $\neg \varepsilon . Y \wedge \uparrow$ & $\leqslant 0$ & Mo.VI & ro & $\wedge$ & $\wedge$ \\
\hline$r \cdot .7 r q$ & $\wedge r . \wedge !$ & $1 \sqrt{1 V 7}$ & $Y . \wedge \odot V$ & $r$ & $\varepsilon Y . \wedge \odot V$ & $r$. & $0 \leq . Y \wedge \uparrow$ & $r \wedge$ & 9 & 9 \\
\hline$r \leqslant . \wedge \ldots$ & 11.9 .0 & IVY & $0 . V 1 \varepsilon$ & $\varepsilon$ & $\& Y . \wedge \odot V$ & $\mu$. & $01 . \leqslant Y q$ & ry & 1. & 1. \\
\hline r०. & $\wedge 0 . \vee \backslash \leq$ & 11. & $1 . \varepsilon r q$ & 1 & $\varepsilon \ldots \ldots$ & $r \wedge$ & $0 \wedge .0 \vee 1$ & $\leqslant 1$ & 11 & 11 \\
\hline$r v .1 \leq r$ & $\wedge 0 . \vee \backslash \leqslant$ & 11. & 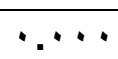 & . & $\varepsilon r . \wedge \odot V$ & $r$. & $0 V .1 \leqslant r$ & $\varepsilon$ & Ir & IY \\
\hline$\varepsilon r . \Delta V r$ & $1 \wedge .90$ & 110 & $\ldots$ & . & ro.VI & ro & $\nearrow \varepsilon . Y \wedge \neg$ & $\leqslant 0$ & ir & 14 \\
\hline
\end{tabular}

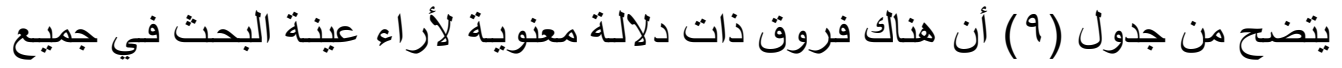

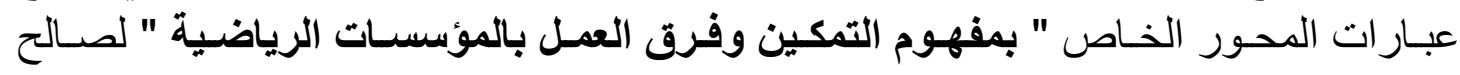

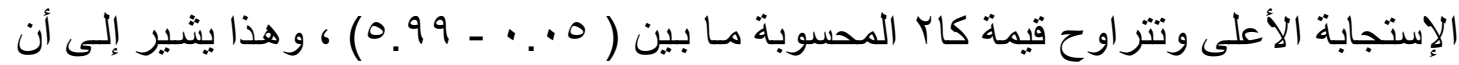

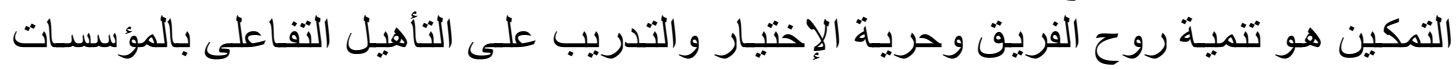

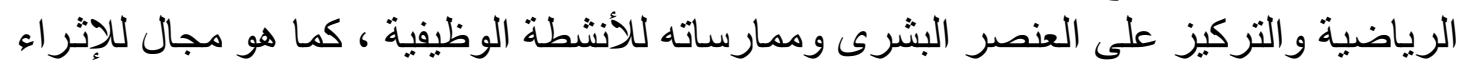

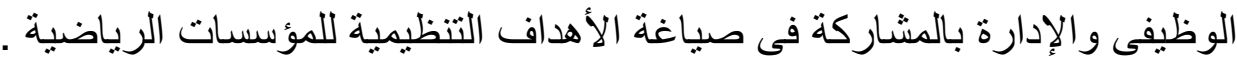

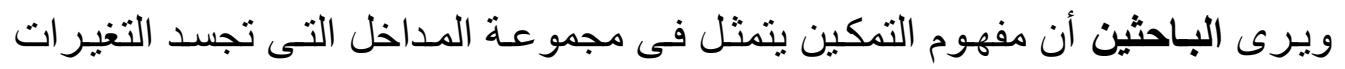

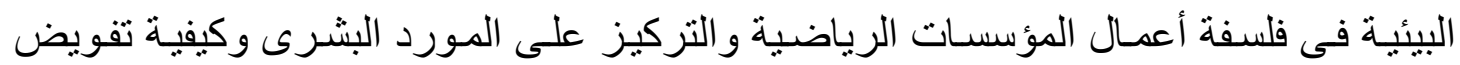

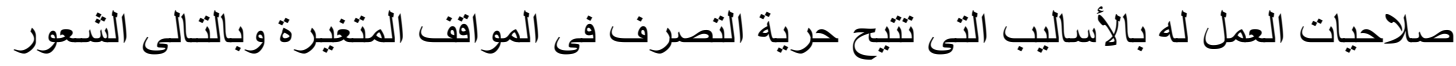

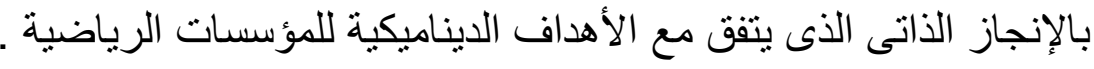

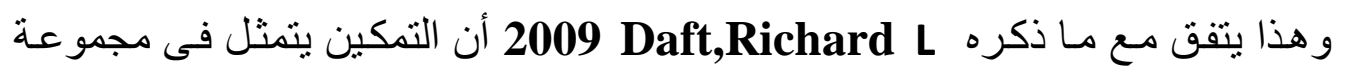

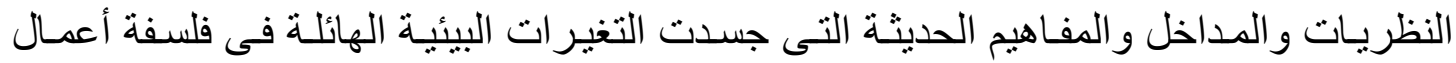

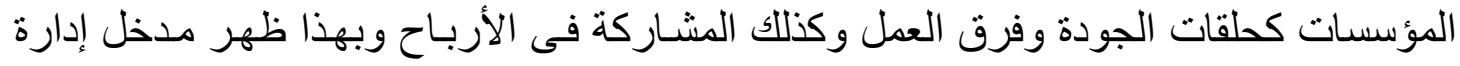

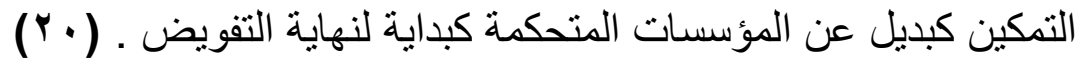

كما يتفق مع ما أشـار إليه كلا من Thyleffors ,I,Persson ,O.Hellston,d

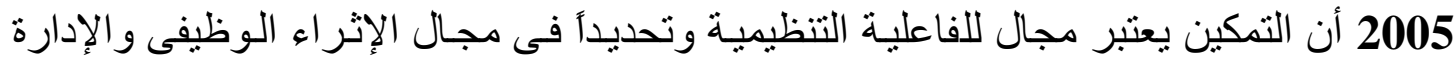

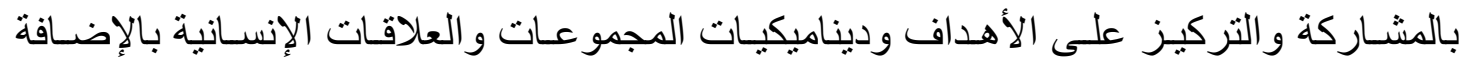
للتعزيز و التغذية العكسية وكذللك التنريب و الجودة و الهيكل التنظيمى . (rV) 
ويتفق مع ما أوصى بـه Daft 2009 أن الإدارات العليا لابد و أن تنظر إلى التمكين

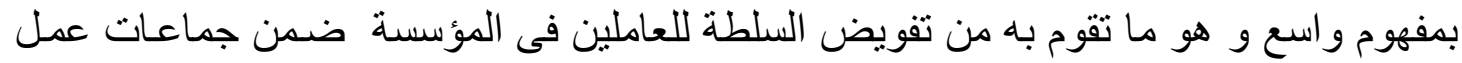

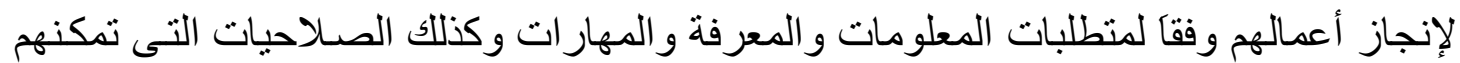

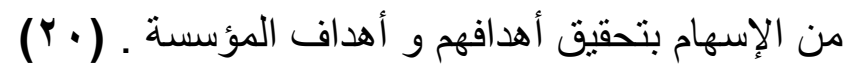

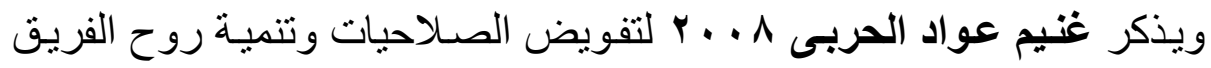

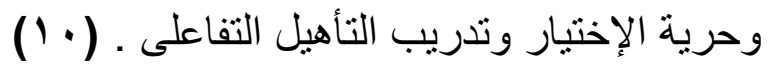

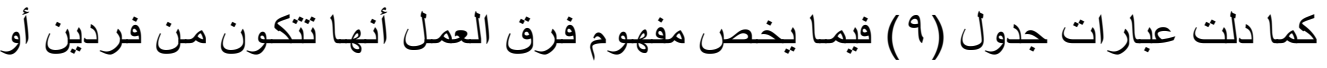

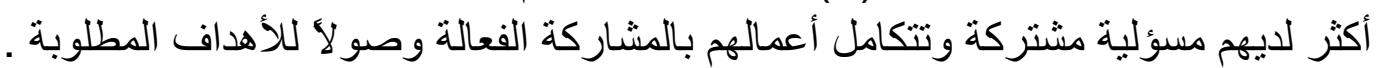

ويرى الباحثين أن فرق العمل هى وحدة تفاعلية تنسق عملهاو تستخدم أسلوبأ معيارياً

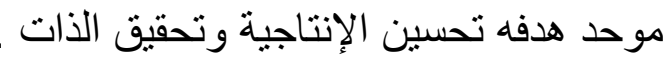

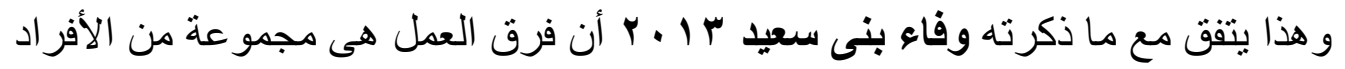

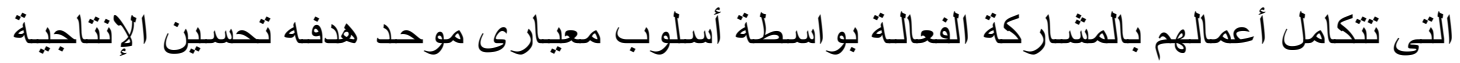
وتحقيق الذات للموظفين القائمين عليه و إعادة تنظيم هياكل الوظيفة . (10)

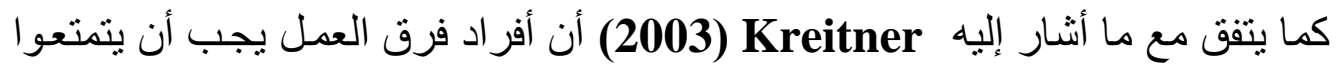

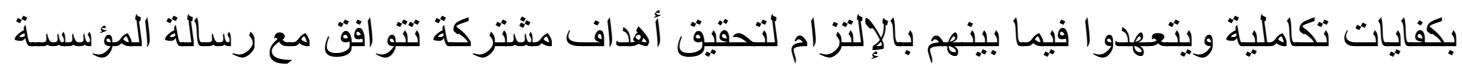

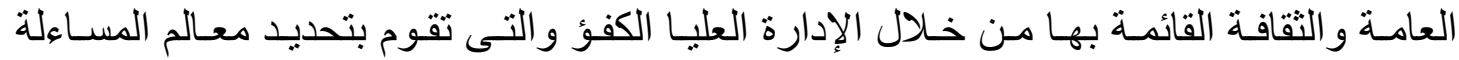

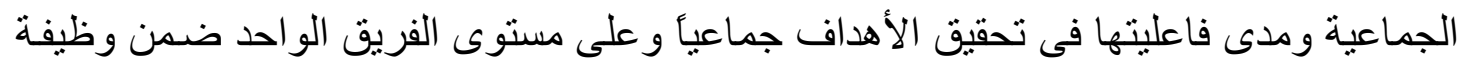

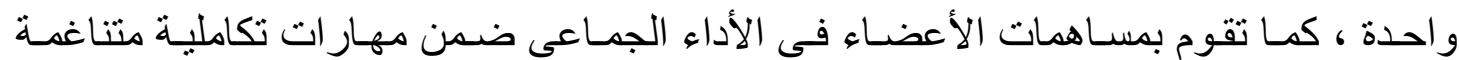

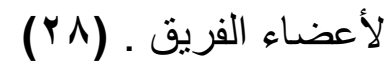

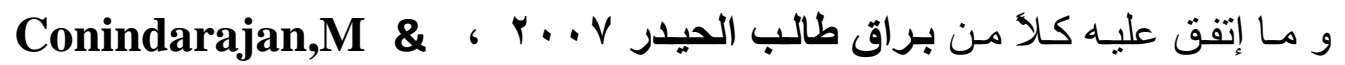
2007 Natarjan وغرضأ مشترك ويعملون مع بعضهم بشكل متناغم وتكاملى ولديهم مسئولية مشتركة وتبادلية

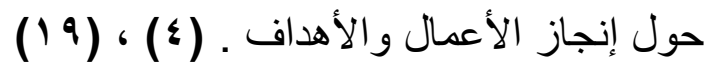




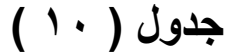

التكرار والنسبة المئوية والوزن النسبي والأهمية النسبية وقيمة كاب لأراء عينة البحث في المحور الثانى الخاص باهمية التمكين وفرق العمل بالمؤسسات الرية الرياضية النية

$V \cdot=\dot{0}$

\begin{tabular}{|c|c|c|c|c|c|c|c|c|c|c|}
\hline \multirow[b]{2}{*}{ كاץ } & \multirow{2}{*}{ |الأهمية } & \multirow{2}{*}{ النسبي } & \multicolumn{2}{|l|}{$y$} & \multicolumn{2}{|c|}{ إلى حـ مـا } & \multicolumn{2}{|c|}{ نعم } & \multirow[b]{2}{*}{ العبارة } & \multirow[b]{2}{*}{$p$} \\
\hline & & & $\%$ & ك5 & $\%$ & ك5 & $\%$ & ك5 & & \\
\hline & & & & & الرياضية & لمق & التمكين بال & أهمب & أ- & \\
\hline$r \ldots$. & $\Lambda \cdot .9 \circ r$ & IV. & $1 \leqslant . Y \wedge 4$ & 1. & YA.OVI & $r$. & $0 V .1 \leqslant r$ & $\varepsilon$. & $1 \varepsilon$ & $1 \varepsilon$ \\
\hline Yr.IVY & $\Lambda 1 . \leqslant Y q$ & $|V|$ & $10 . V 1 \leqslant$ & 11 & $r \leqslant . Y \wedge T$ & IV & $9 . \ldots$ & $\varepsilon r$ & 10 & 10 \\
\hline$r \cdot \ldots$ & $\Lambda \cdot .90 Y$ & IV. & $1 \& . Y \wedge 4$ & 1. & Y^.०VI & $r$. & $\Delta V .1 \leqslant r$ & $\varepsilon$. & 17 & 17 \\
\hline$\varepsilon r . \diamond V Y$ & 11.90 & 110 & $\therefore \cdots$ & . & ro.vis & ro & Tะ.Y人T & $\leqslant 0$ & IV & IV \\
\hline & & & & & سلة الرياضي & المؤد & فرق العمل & أهمب & ب- & \\
\hline$r \leqslant . \wedge \ldots$ & $\vee q . \cdot \leq 1$ & 179 & $0 . V 1 \leq$ & $\varepsilon$ & $01 . \varepsilon Y q$ & rq & $\varepsilon Y . \wedge \odot V$ & $r$. & 11 & 11 \\
\hline 01.1 .1 & $9 . \ldots$ & 119 & $\because \cdots$ & . & $\mu . .$. & YI & $v \cdot . .$. & $\leqslant 9$ & 19 & 19 \\
\hline$\leqslant 9 . \leqslant \wedge q$ & Aq.०Y\& & $1 \wedge 1$ & $\because \cdots$ & . & $r 1 . \varepsilon r q$ & Yr & $71.0 V 1$ & $\varepsilon \wedge$ & $r \cdot$ & $r \cdot$ \\
\hline rq.r. I & $17.77 \mathrm{~V}$ & INY & $\because \cdots$ & - & $\varepsilon \ldots$ & $r \wedge$ & $7 . .$. & $\varepsilon r$ & YI & YI \\
\hline
\end{tabular}

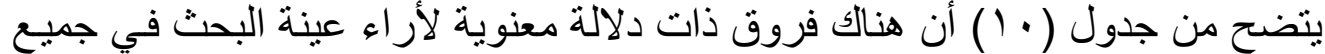

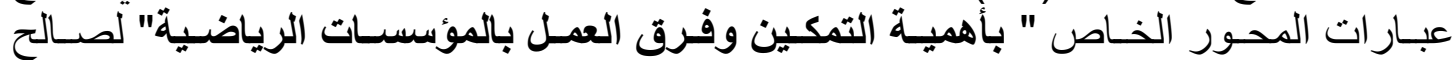

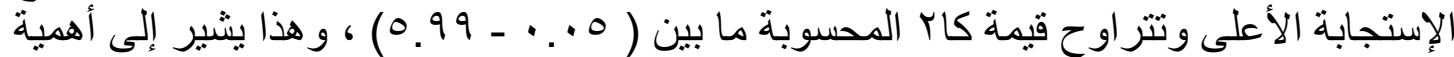

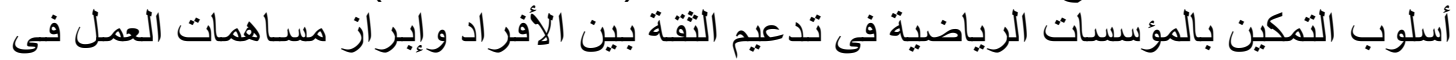

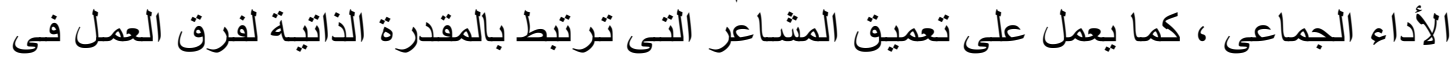

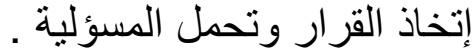

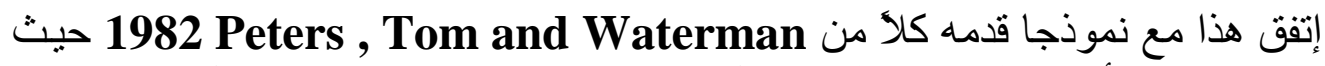

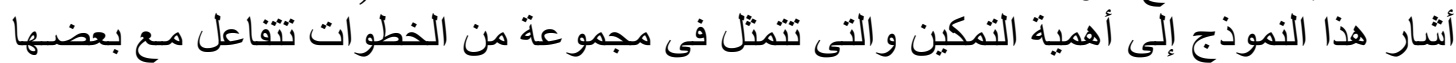

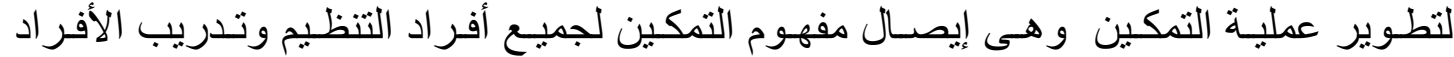

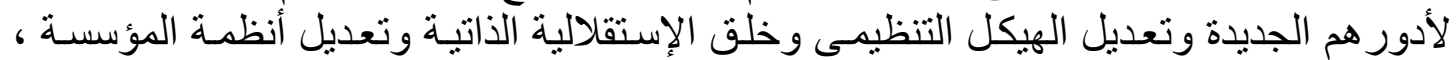

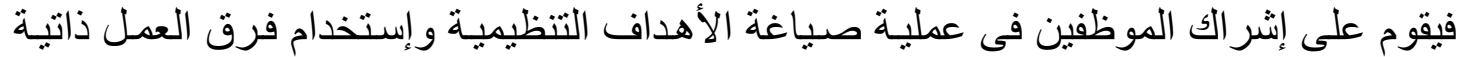

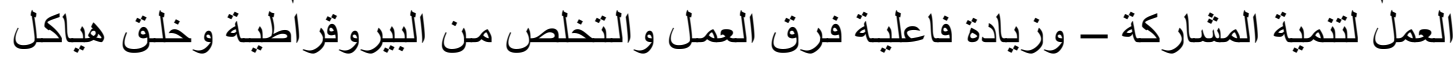

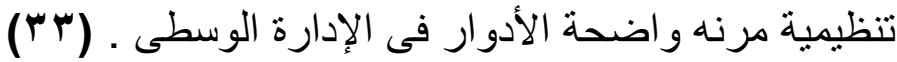




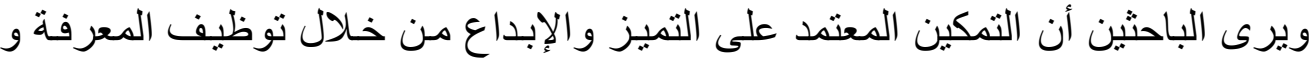

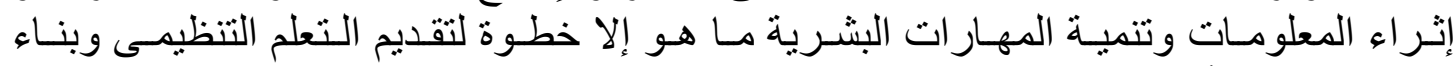

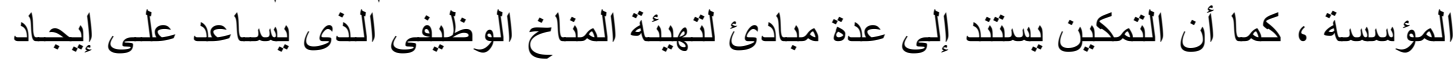

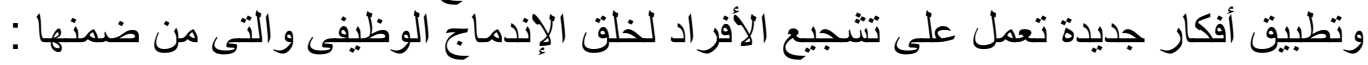

ـ ـ معرفة وتحديد المسؤليات للأفر اد ـ و التخلى عن السلطات السساوية للمسؤليات لدى

$$
\text { الأفراد . }
$$

- تحديد الإنجاز المتميز والإعتر اف به وكذلك دعم الثقة للأفر اد .

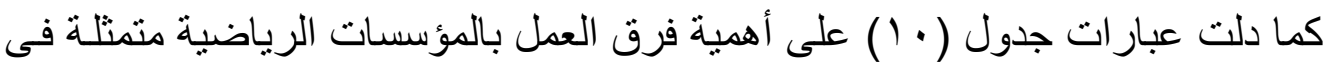

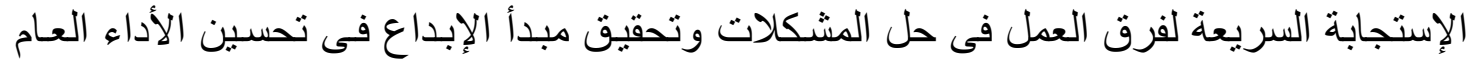

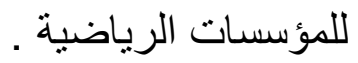

و هذا ما يتفق مع ما توصلت إليه هيام الثريدة م . . ب بأهمية فرق العمل لمـا تمتلكه

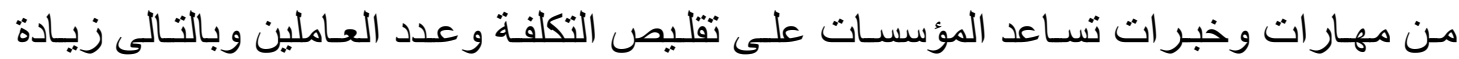

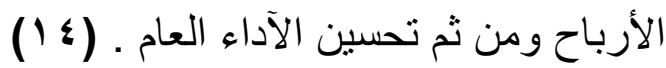

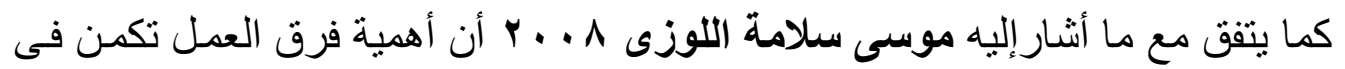

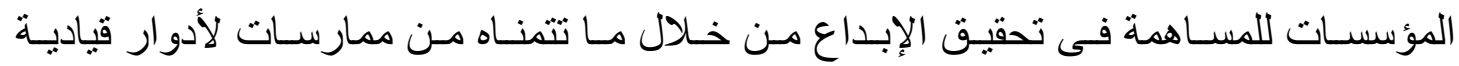

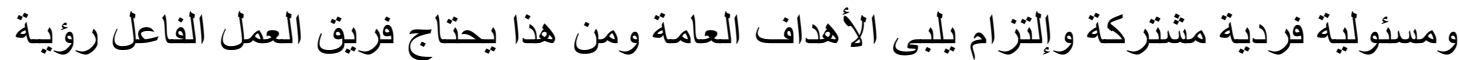

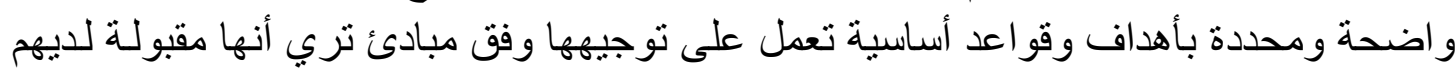

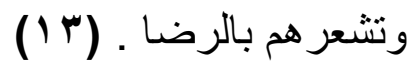

ويرى الباحثين أن فرق العمل تمتلك مزيجاً من المهارات التكاملية التى تمكنها من

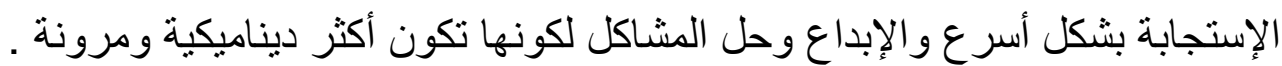

جدول (11)

التكرار والنسبة المئوية والوزن النسبي والأهمية النسبية وقيمة كاب لأراء عينة البحث في المحور الثالث الخاص بأبعاد التمكين بالمؤسسات الرياضية الأية

\begin{tabular}{|c|c|c|c|c|c|c|c|c|c|c|}
\hline \multirow[b]{2}{*}{ كاץ } & \multirow{2}{*}{ الأهمية } & \multirow{2}{*}{ النسبي } & \multicolumn{2}{|l|}{$y$} & \multicolumn{2}{|c|}{ إلى حد مـا } & \multicolumn{2}{|l|}{ نعم } & \multirow[b]{2}{*}{ العبارة } & \multirow[b]{2}{*}{ p } \\
\hline & & & $\%$ & ك5 & $\%$ & ك5 & $\%$ & 5 & & \\
\hline$r r . r \varepsilon r$ & $\Lambda Y . r \wedge I$ & IVT & $1 \ldots$ & $\mathrm{V}$ & rY.AOV & $r r$ & $0 V .1 \leqslant r$ & $\varepsilon$ & YY & YY \\
\hline$r \ldots$. & $V 1 . \leqslant Y q$ & 10 & $1 \& . Y \wedge q$ & 1. & $0 V .1 \leqslant r$ & $\varepsilon$. & $r \wedge . \Delta V I$ & $r$. & $r r$ & $r r$ \\
\hline$r . . r$. & $\wedge \varepsilon . Y \wedge \neg$ & IVV & $\varepsilon . Y \wedge 4$ & $r$ & rA.०VI & $r V$ & $0 V .1 \leqslant r$ & $\varepsilon$. & $Y \varepsilon$ & $r \leqslant$ \\
\hline$r v .910$ & $17.77 \mathrm{~V}$ & INY & $\varepsilon . Y \wedge 4$ & $r$ & $r 1 . \leqslant r_{q}$ & YY & Tะ.YAT & $\leqslant 0$ & ro & ro \\
\hline
\end{tabular}




\begin{tabular}{|c|c|c|c|c|c|c|c|c|c|c|}
\hline$r V . \wedge \ldots$ & $\wedge r . \wedge 1$. & $1 V 7$ & $V .1 \leqslant r$ & 0 & 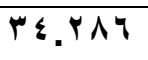 & $r \varepsilon$ & $0 \wedge .0 V 1$ & $\leqslant 1$ & $Y 4$ & Yq \\
\hline$\leqslant \wedge .0 \leqslant \leqslant$ & $\wedge q . \leqslant 1$ & $1 \wedge V$ & $Y . \wedge \odot V$ & $r$ & $r V .1 \leqslant r$ & 19 & $v \cdot . .$. & $\leqslant 9$ & YV & YV \\
\hline$r \cdot r \ldots$ & $\wedge \varepsilon . Y \wedge \bar{T}$ & IVV & $\varepsilon . Y \wedge \neg$ & $r$ & rᄉ.०VI & PV & $0 V .1 \leqslant r$ & $\varepsilon$. & $r \wedge$ & $r \wedge$ \\
\hline ro. Yrq & $\Lambda Y . \wedge \odot V$ & $I V \varepsilon$ & $V .1 \leqslant r$ & 0 & $r V .1 \leqslant r$ & Yq & $00 . V I \leq$ & $r q$ & rq & rq \\
\hline$r r .1 \leqslant r$ & $\Lambda \cdot .90 r$ & IV. & $V .1 \leqslant r$ & 0 & $\varepsilon Y . \wedge \odot V$ & $r$. & $0 . .$. & ro & r. & $\mu$. \\
\hline $0 \& . Y \wedge Y$ & $9 \cdot . \varepsilon V 7$ & 19. & $\because \cdots$ & . & YA.०VI & $r \cdot$ & $V 1 . \leqslant Y q$ & 0 . & $m$ & $r$ \\
\hline$r q . \& Y q$ & Mr.Mr & IVO & $V .1 \leqslant r$ & 0 & ro.VI\& & ro & $0 V .1 \leqslant r$ & $\varepsilon$. & $r r$ & $r r$ \\
\hline
\end{tabular}

يتضح من جدول (1) أن هناك فروق ذات دلالة معنوية لأراء عينة البحث في جميع

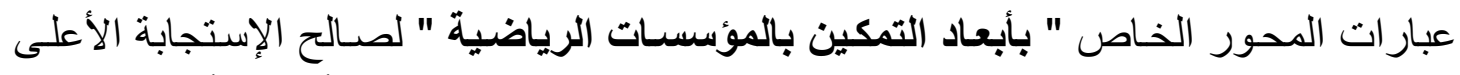

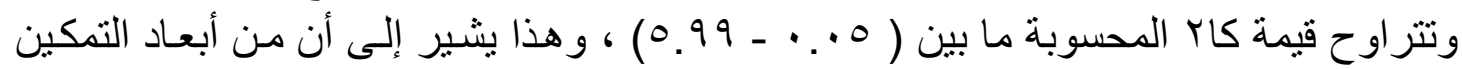

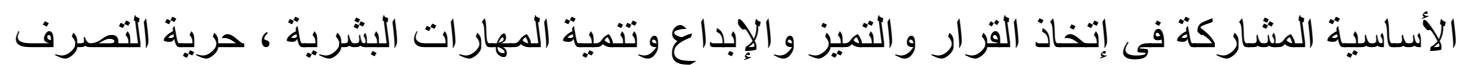

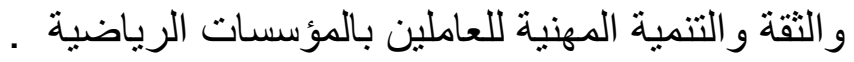

ويرى الباحثين أن التمكين له عدة أبعاد و التى من أهمها إتاحة المعلومات و البيانات عن

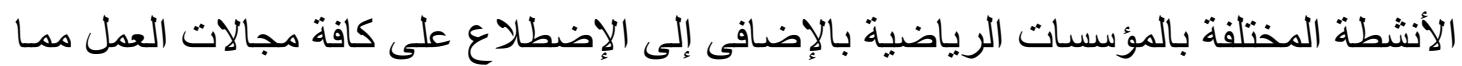

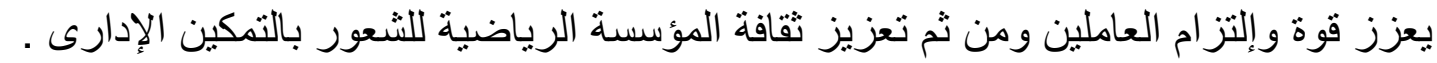

وهذا يتفق مع ما ذكره 1993 Eccles,Tony أن مـا تتبنـاه إدارة المؤسسـة الرياضية

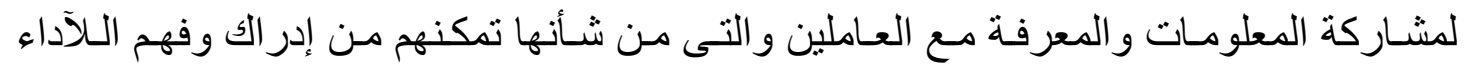
( التظيمى . ( ) ( )

كما يتفق مـع رأى كلا من 1995 Bown , Lawer التمكين بأنه المشـاركة الفعليـة بين المستويات الإدارية فى بيئة العمل و التى يحددها فى أربعة عناصر أساسية وهى المعلومات

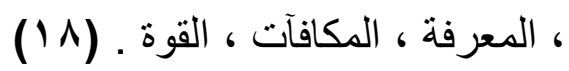
و ما توصل إليه 2003 Daft أن أبعاد التمكين تتجسد فى :

$$
\begin{aligned}
& \text { - - - ماتاحة المعلومات . } \\
& \text { - - }
\end{aligned}
$$

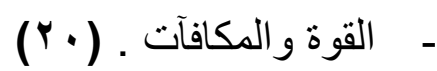

و أضاف 2003 Melhem, Yahaya الثقة بين العاملين فى مستويات الإدارة . 


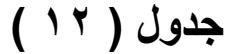

التكرار والنسبة المئوية والوزن النسبي والأهمية النسبية وقيمة كاب لأراء عينة البحث

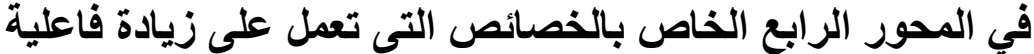
فرق العمل بالمؤسسات الرياضية

$V \cdot=\dot{U}$

\begin{tabular}{|c|c|c|c|c|c|c|c|c|c|c|}
\hline \multirow[b]{2}{*}{ كاץ } & \multirow{2}{*}{ الأهمية | النسبية } & \multirow{2}{*}{ النسبي } & \multicolumn{2}{|l|}{$y$} & \multicolumn{2}{|c|}{ إلى حد ما } & \multicolumn{2}{|c|}{ نعم } & \multirow[b]{2}{*}{ العبارة } & \multirow[b]{2}{*}{$\beta$} \\
\hline & & & $\%$ & ك5 & $\%$ & 5 & $\%$ & 5 & & \\
\hline$r r . r \leq r$ & AY.rAI & IVr & $1, \ldots$ & $\mathrm{V}$ & rY.AOV & $r r$ & $\Delta V .1 \leqslant r$ & $\varepsilon$. & rr & $r r$ \\
\hline$r r .1 \leqslant r$ & $\Lambda \cdot .9 \circ r$ & IV. & $V .1 \leqslant r$ & 0 & $\varepsilon Y . \wedge \odot V$ & $r$. & $0 . .$. & ro & $r \varepsilon$ & $r \varepsilon$ \\
\hline$r 0 . \mu \varepsilon r$ & $\wedge \varepsilon . Y \wedge \neg$ & IVV & $\because \cdots$ & . & $\varepsilon V .1 \leqslant r$ & $r r$ & $\Delta$ Or.AOV & $r v$ & ro & ro \\
\hline $19.70 \mathrm{~V}$ & VA. 90 & $17 \varepsilon$ & $\Lambda .0 V 1$ & 7 & $\leqslant \wedge . \diamond \vee \backslash$ & \& & $\varepsilon Y . \wedge \odot V$ & $r$. & T & rq \\
\hline$\varepsilon r . \Delta V Y$ & $11 . \cdot 90$ & 110 & $\because \cdots$ & . & ro.VI\& & ro & T\&.Y人T & $\leqslant 0$ & $\mu v$ & $r v$ \\
\hline$\varepsilon r . Y . I$ & $1 V .719$ & $1 \wedge \varepsilon$ & \&.YAฯ & $r$ & r^.०VI & $r$. & $T V .1 \leqslant r$ & $\varepsilon V$ & $r \wedge$ & $\mu \wedge$ \\
\hline$r r .1 \leqslant r$ & $\Lambda \cdot .90 r$ & 18. & $v .1 \leqslant r$ & 0 & $\varepsilon Y . \wedge \odot V$ & $r$. & $0 . . \cdots$ & ro & $r q$ & $r q$ \\
\hline$\neg \vee . . \Delta \wedge$ & 91.9 .0 & 194 & Y.A०V & $r$ & $\mid \wedge .0 \vee 1$ & $1 r$ & $\vee \wedge . \Delta \vee I$ & 00 & $\varepsilon$. & $\varepsilon$. \\
\hline $7 \varepsilon .701$ & 91.9 .0 & 194 & $1 . \varepsilon Y q$ & $T$ & $r 1.8 Y q$ & 10 & $V V .1 \leqslant r$ & $0 \leqslant$ & \&1 & $\leqslant 1$ \\
\hline$\leqslant \wedge .0 \leqslant \leqslant$ & $\wedge q . \leqslant \wedge$ & $1 \wedge V$ & Y.A०V & $r$ & $r V .1 \leqslant r$ & 19 & $v \cdot . .$. & $\leqslant 9$ & $\varepsilon r$ & $\varepsilon r$ \\
\hline
\end{tabular}

يتضح من جدول (Y I ) أن هناك فروق ذات دلالة معنوية لأراء عينة البحث في جميع

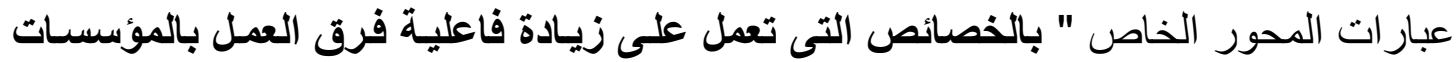

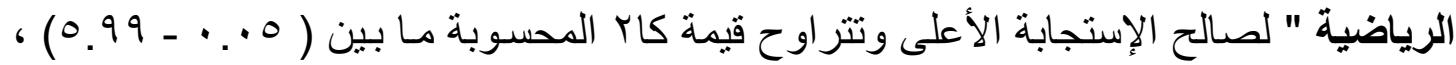

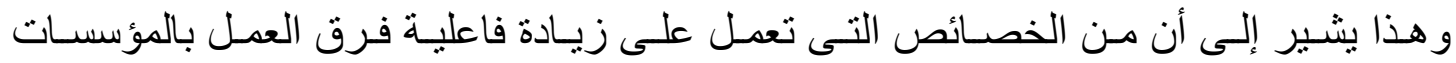

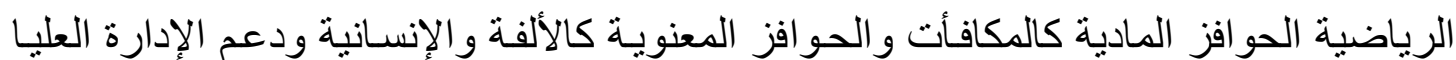
لفرق العمل ، القيادة والتنوع فى الأدوار الإدارية والأداء الجاء الجماعى .

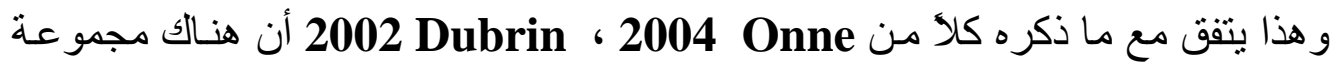

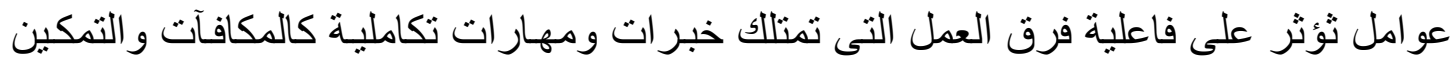

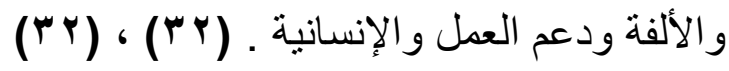

ومـع مـا ذكره 2004 Hellrigel et.al الخارجية المحيطة بالعمل و المعايير و التماسك و القيادة و الأهداف و الأدوار ومدى تنو عها لتها . (ro) 
و إتفق هذا مـع رأى 2003 Robbins et.al أن فاعلية فرق العمل تتأثر بالهدف والجديـة

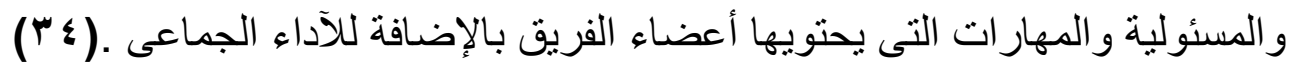

ويرى الباحثين أن أهم الخصـاص التى تعمل على زيـادة فاعلية فرق العمل تصميم

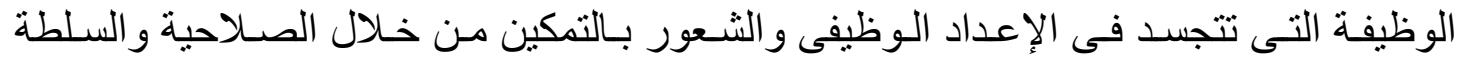

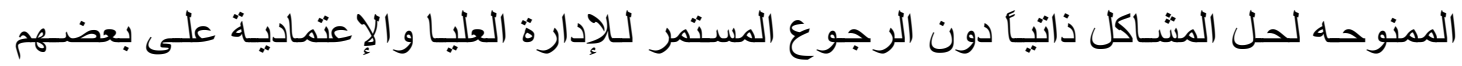

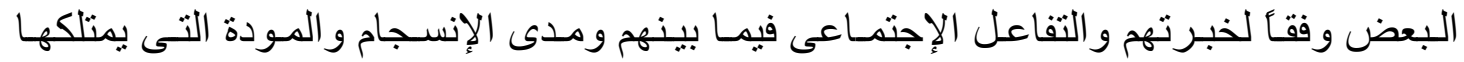
أعضاء الفريق . أبعض

إستخلاصات البحث فى ضوء هدف البحث ، والعينة المستخدمة والتحليل الأحصائى وما تم التوصل إليه من نتائج

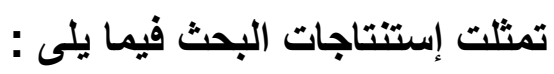

إستخلاصـات فـى ضـوء المحسور الأول مفهـوم التمكين وفـرق العمل بالمؤسســات

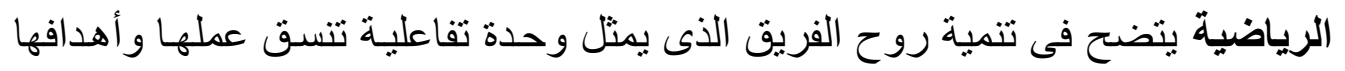

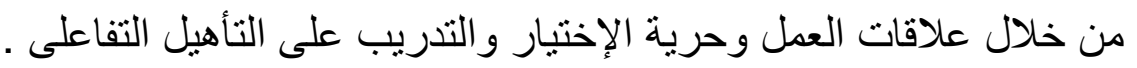

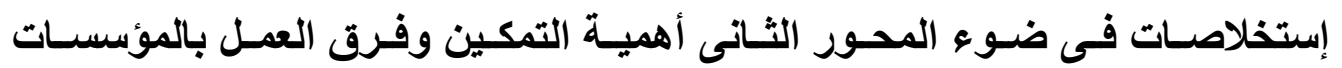

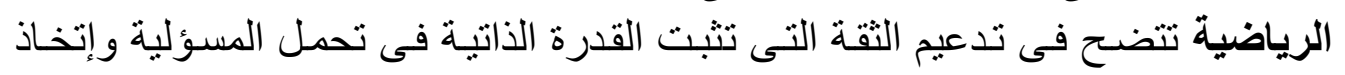

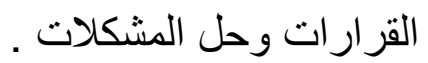

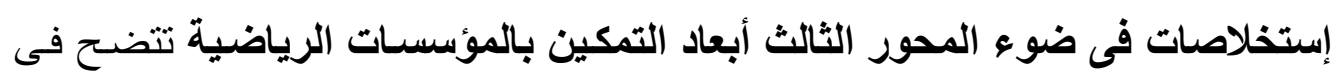

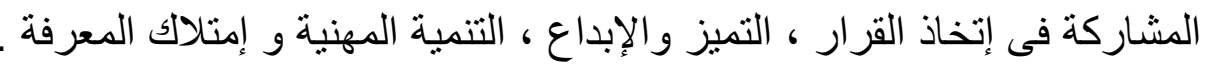

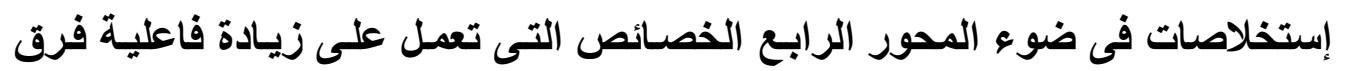

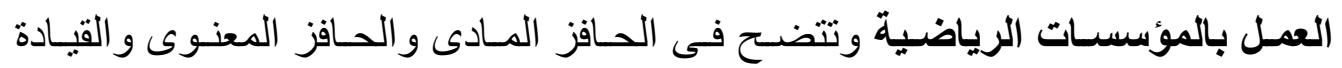

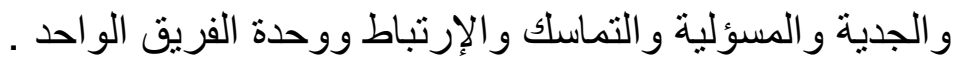


توصيات البحث

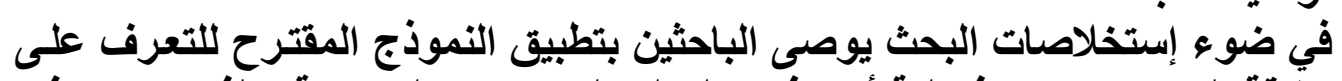

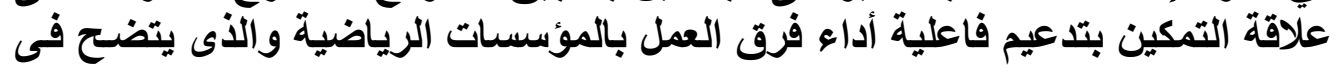

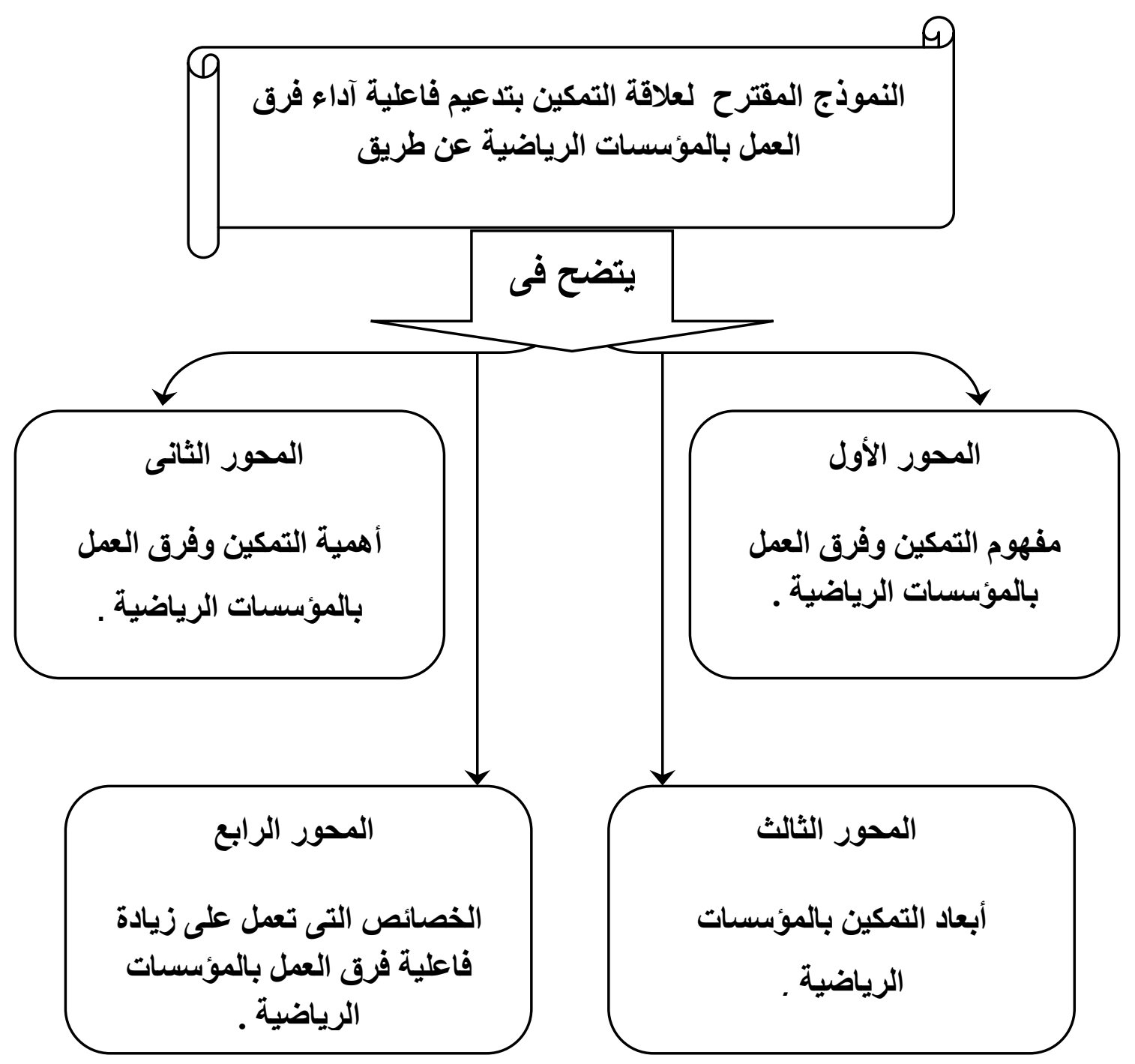


لتطبيق النموذج المقترح يجب الإسترشاد بنتائج محاور الإستبيان كما هى موضحة فى الأتى :

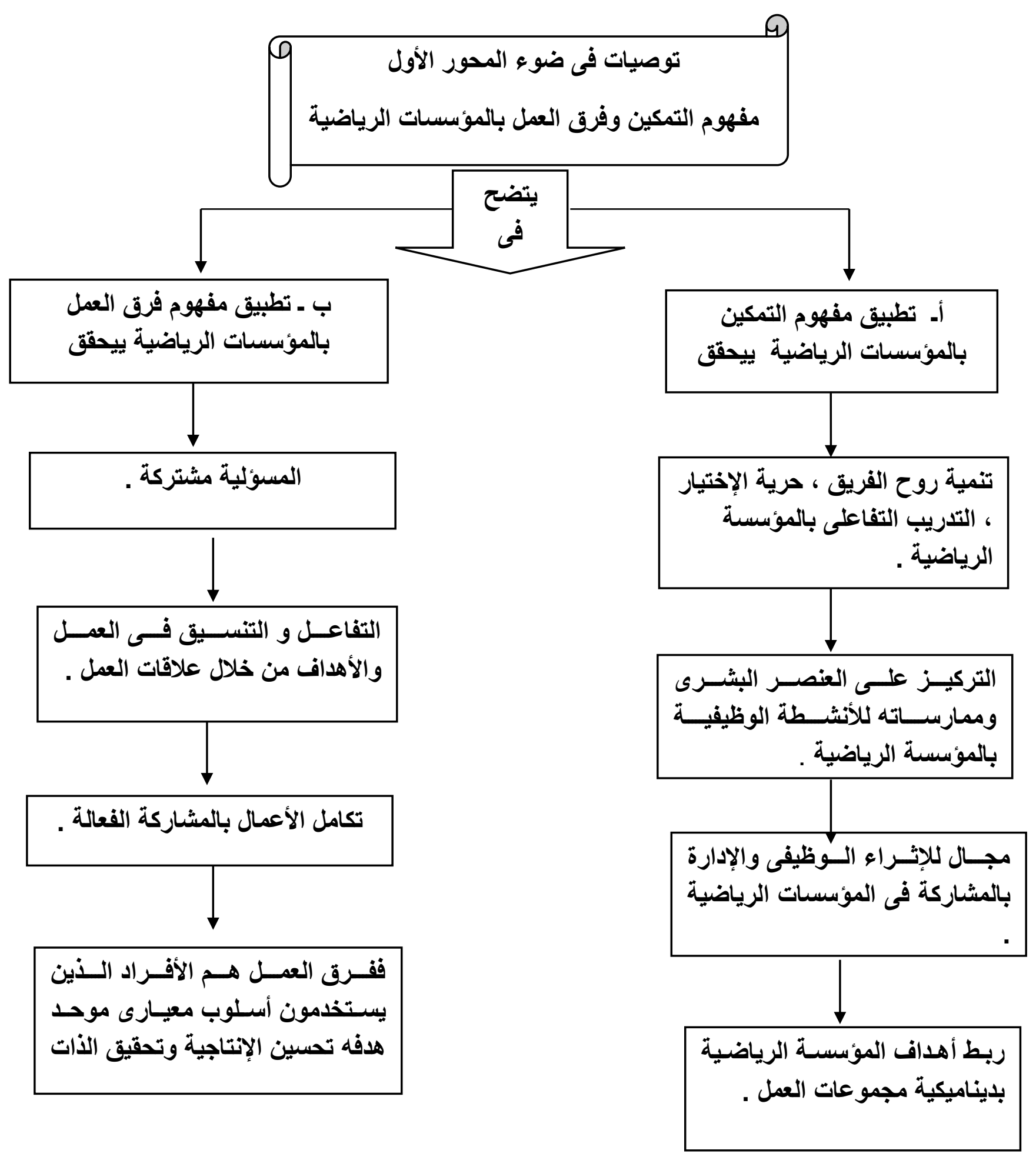




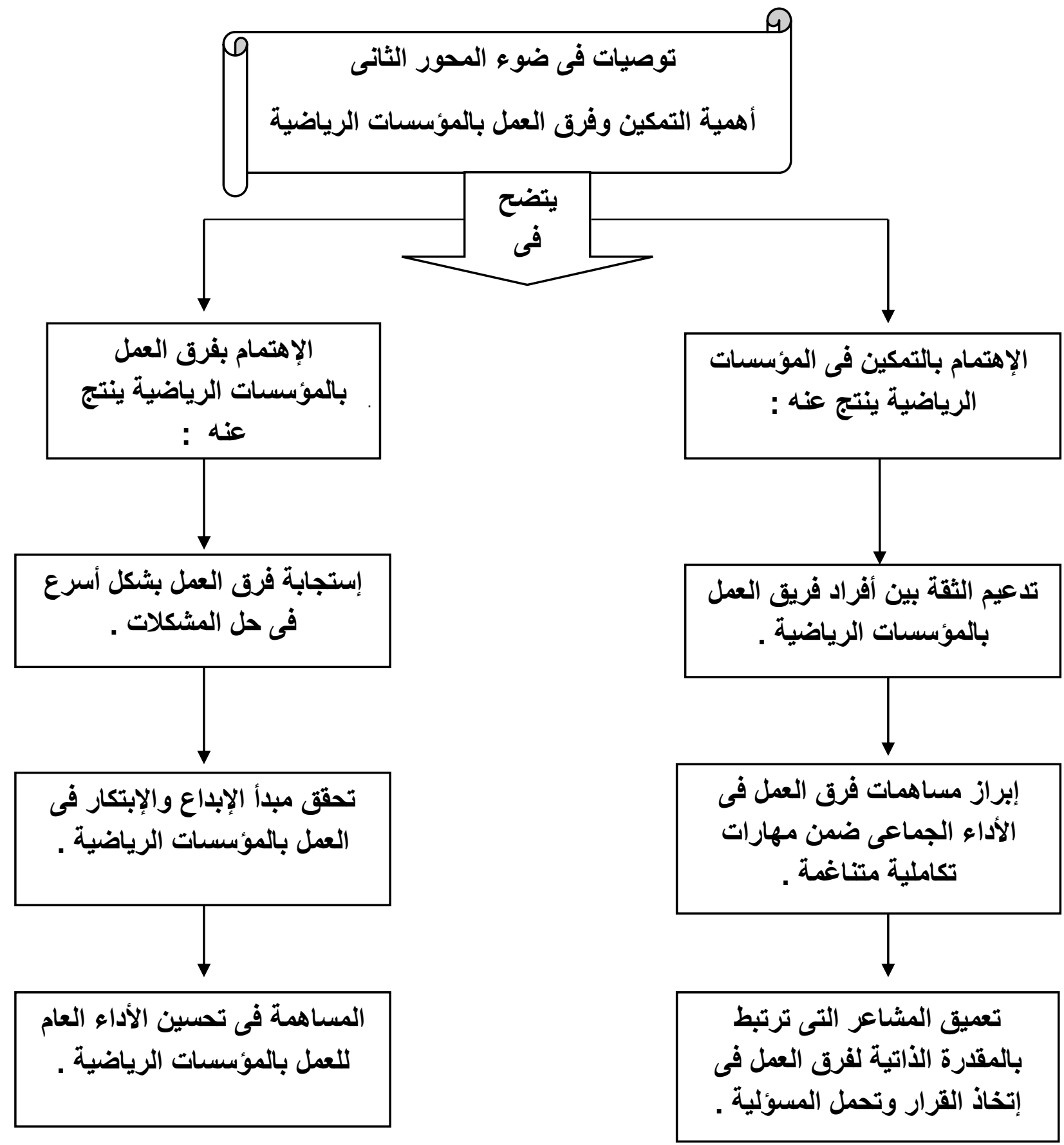




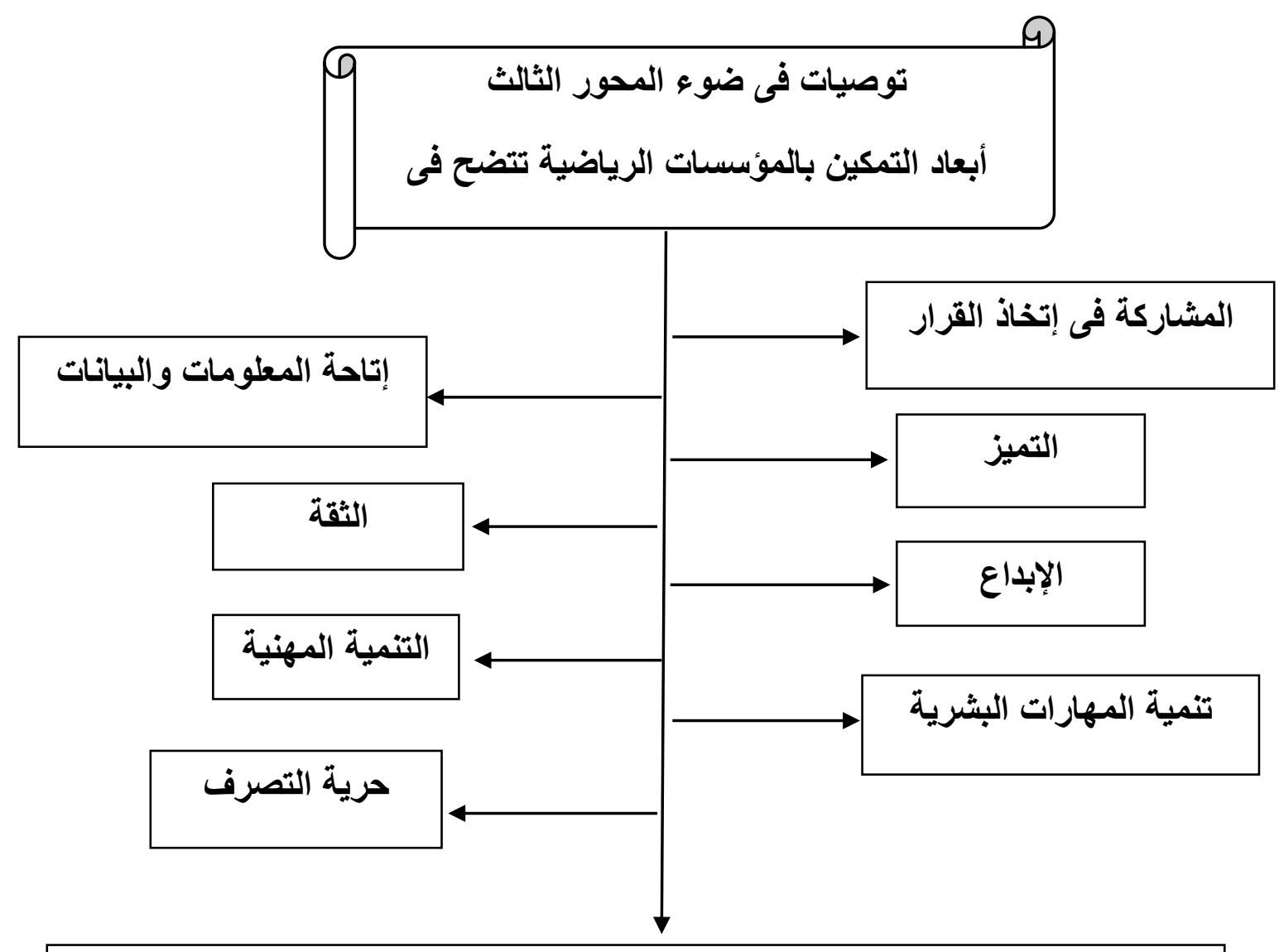

و تطبيق إبعاد التمكين يعزز قوة وإلتزام العاملين فينتج عنه تعزيز ثقافة المؤسسة الرياضية وصولاً للتمكين الإدارى
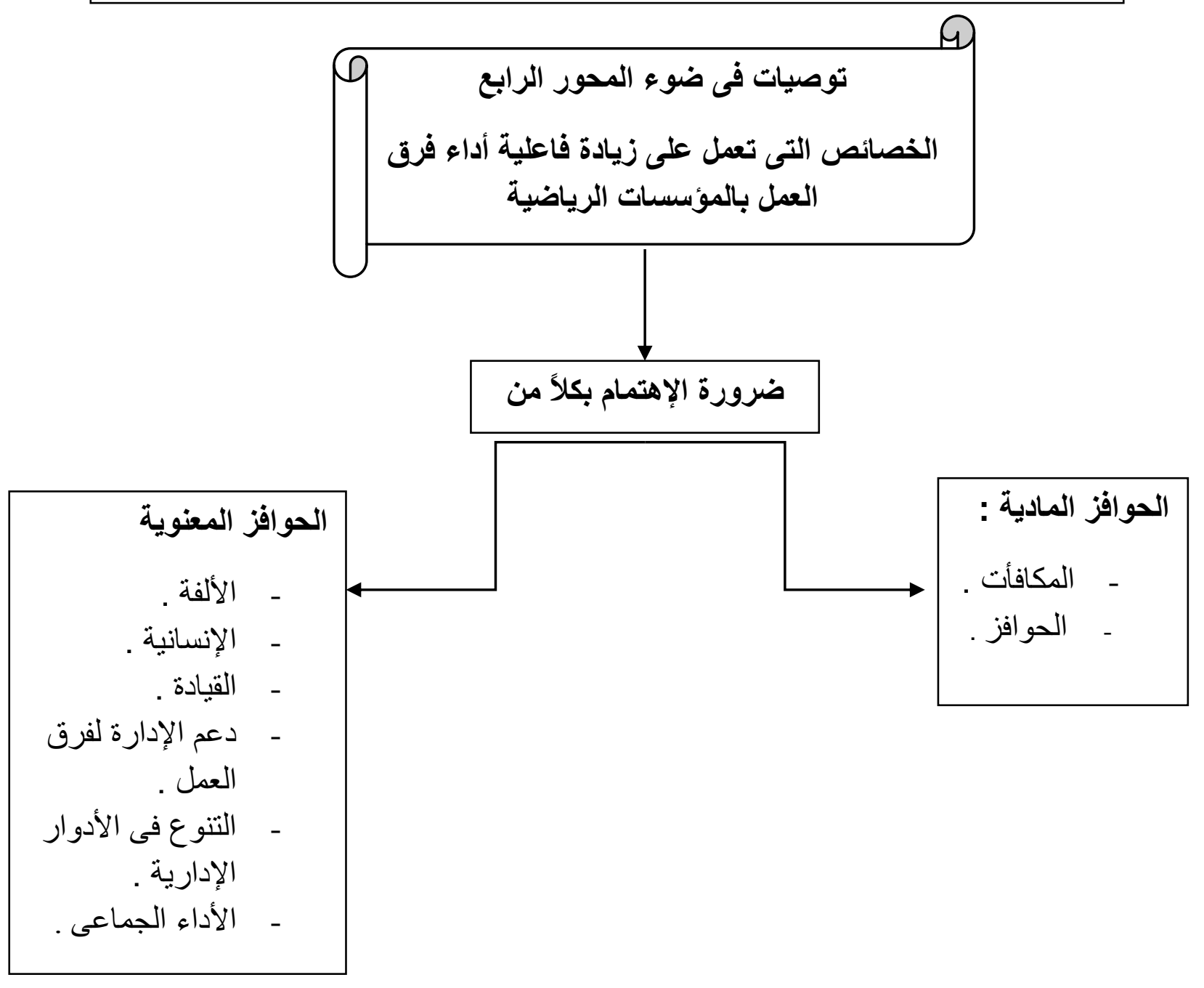


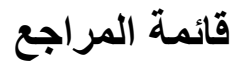

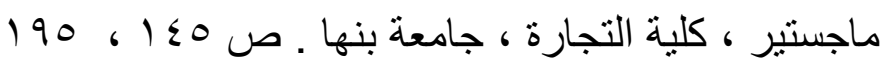

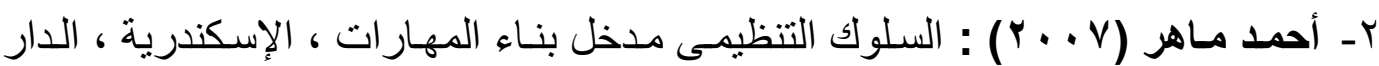

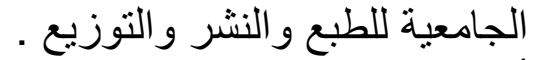

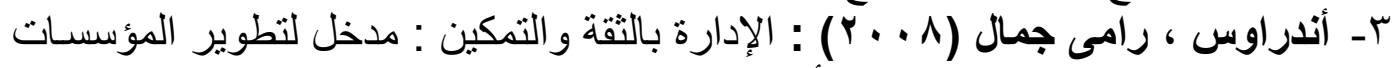

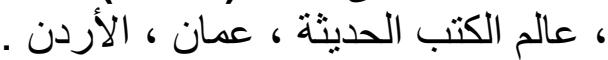

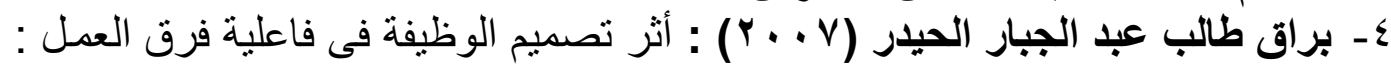

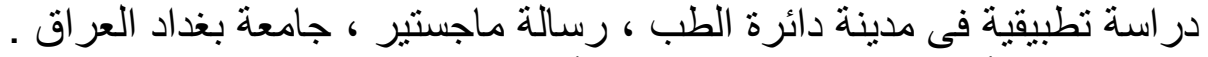

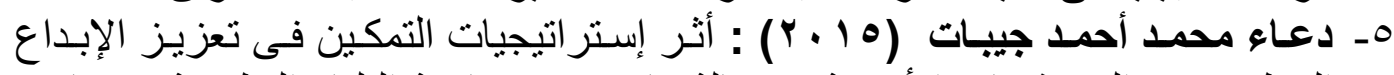

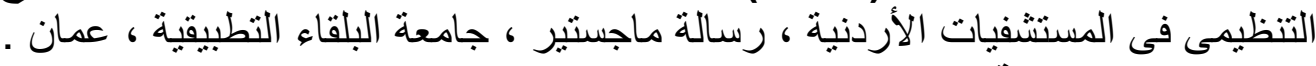

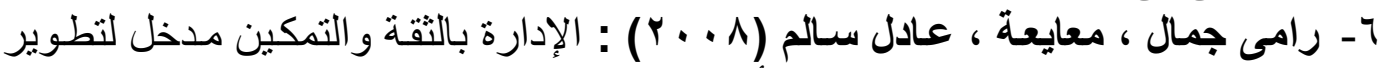

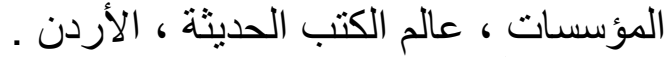

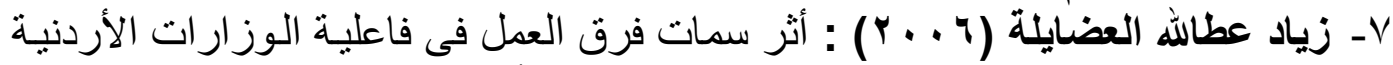

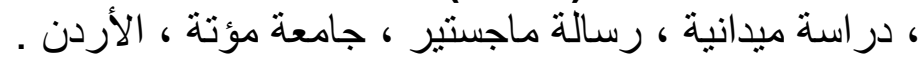

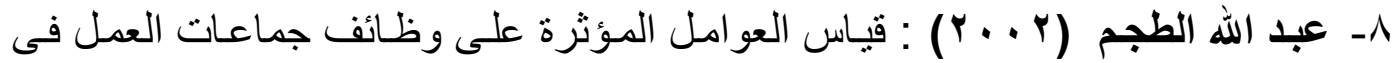

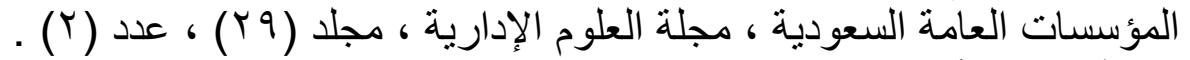

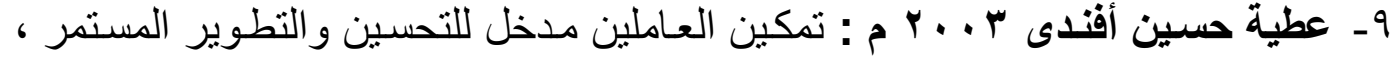

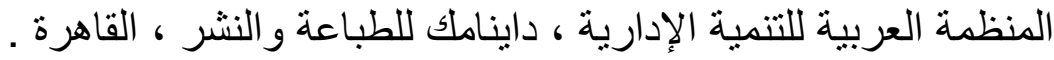
•

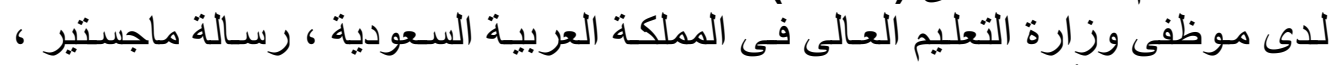

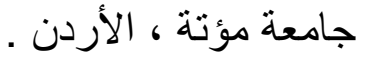

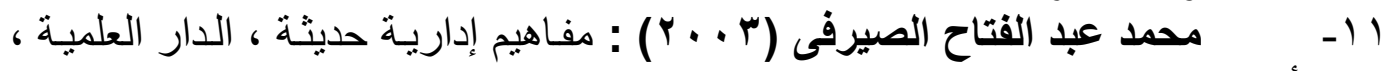

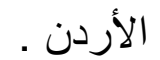

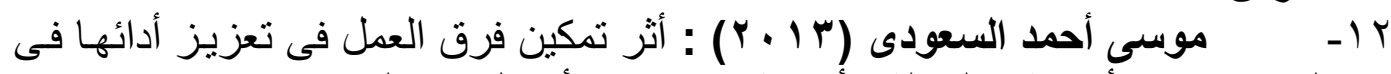

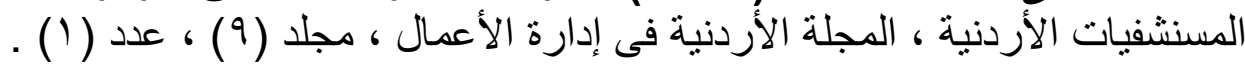

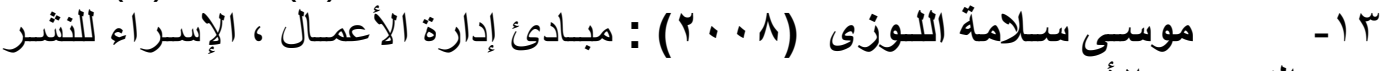

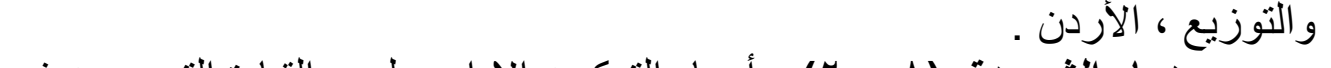

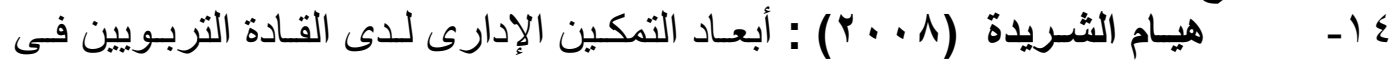

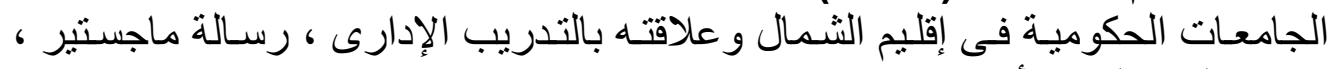

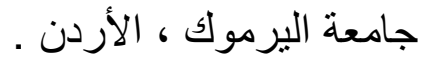

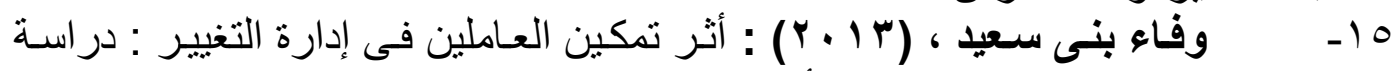

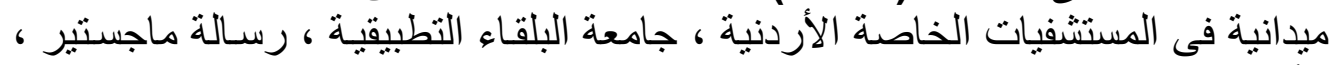

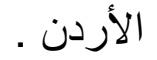




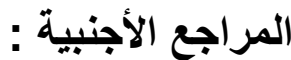

16- Amr,Abou Elnaga , and Amen, Imran (2014) : The Impact of Employee Empowerment on Jop Satisfaction : Theoretical study , American Journal of Research Communication . vol,(2), No,(1) .USA.

17- Bennis,R Townsend (1995) : "Reinveting Leader Ship" newYork, willian morrow .

18- Bowen,D.F\&Lawler,E.E (1995) : Empowering service Employess sloen Management review,summer.

19- Conindarajan, $M$ and Natarjan, S, (2007), principles of Management prentice-Hall of India private Limited - New Delhi, India .

20- Daft,Richard L.(2009), organizational Theory and Design,8thed.,Tomson-south-western,ohio.

21- Daft,Richard L.(2003), organizational Theory and Design.3th ed.,Tomson-south-western,ohio.

22- Daft,Richard L.(2000), "Management",6thed.,Harcort college publishing, Orlando.

23- Dubrin , Andrew J.,(2002) Fundamentals of Chmiel, Nik,"Introduction to work and organizational pshychology",1st ed., Black Well Publishers, Oxford, UK.

24- Eccles ,Tony ,(1993), The Deceptive Allure OF Empowerment, Long to team think, Emerald,work study,Vol.(52),No.(5).

25- Hellrigel , Don , Slocum, J and Woodman Richard,w., (2004)"'Organizational Behavior", 10th ed., southwestern College, Publishing in USA.

26- Invancevich ,John $M$, and Michael T.,(2002), organization Behavior and Management ,6thed., Mc Graw-Hall,Irwin.

27- James Becker (2001) : The important of individual performance from the perspective of gnome and ongoingational performance effectiveness ' small group research ' vol 32.

28- Kreitner,R., Kinichia, A., \& Cole, N.,(2003). Fundamentals of Organizational Behavior, First Edition, Canada: McGraw Hill.

29- Melhem,Yahaya (2003)."Employee-Customer Relationship: An Investigation In To the Impact of Customer-contact, 
Unpublished PhD Dissertation, University of Nottingham, England

30- Mendibil, Kepa, \& Mabryda, J.,(2006). Factor That Affect the Design and Implementation of Team-Based Performance Measurement Systems, International Journal of Productivity and Performance Management,55(2).

31- Oberty, O., \& Saa-Peres P., (2006). Work Teams to Favor Knowledge Management, European Business Review,81(1).

32- Onne, Jansdsen,(2004)"The Barries effect of conflict with superioes in the relationships between empowerment and organizational commitments",. Work and stress , Vol.18,No.(1).

33- $\quad$ Peres, Tom and Waterman, Robert,(1982), In search of Excellence: Lessons from America Best Run Companies,London,Haper and Row.

34- Robbins,StephnP ., (2003). Organizational Behavior : Concepts., Controversies, Application, Prentice-Hall International, Inc., New York.

35- Simons,Robert,(1995),Control In An Age Ideology, Organization Studies, Vol.(123),No.(3).

36- Spector (1995) "Taking changes \& Letting go "New York, the free press .

37- Thyleffors ,I,Persson ,O.Hellston,d (2005), Perceived efficiency and Teamwork,Journal of Intor professional car,vol.(19),No(2)

38- Wikinsons, A(1998). "Empowerment: theory and practice", Personal Review, Vol.(27)No.(1). 